\title{
Used Fuel Disposition Research and Development Roadmap - FY10 Status
}

Fuel Cycle Research \& Development

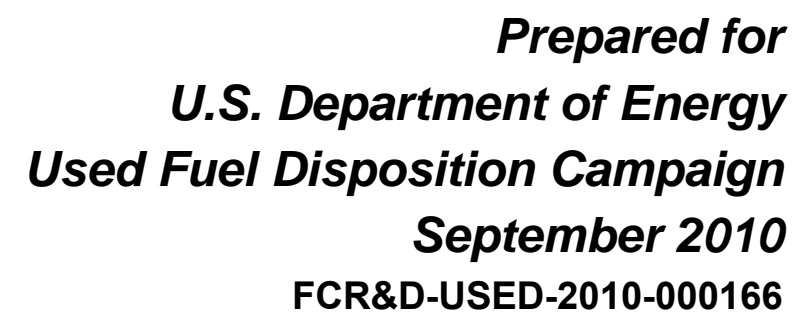




\section{DISCLAIMER}

This information was prepared as an account of work sponsored by an agency of the U.S. Government. Neither the U.S. Government nor any agency thereof, nor any of their employees, makes any warranty, expressed or implied, or assumes any legal liability or responsibility for the accuracy, completeness, or usefulness, of any information, apparatus, product, or process disclosed, or represents that its use would not infringe privately owned rights. References herein to any specific commercial product, process, or service by trade name, trade mark, manufacturer, or otherwise, does not necessarily constitute or imply its endorsement, recommendation, or favoring by the U.S. Government or any agency thereof. The views and opinions of authors expressed herein do not necessarily state or reflect those of the U.S. Government or any agency thereof. 


\section{SUMMARY}

Since 1987 the U.S. has focused research and development activities relevant to the disposal of commercial used nuclear fuel and U.S. Department of Energy (DOE) owned spent nuclear fuel and high level waste on the proposed repository at Yucca Mountain, Nevada. At the same time, the U.S. successfully deployed a deep geologic disposal facility for defense-related transuranic waste in bedded salt at the Waste Isolation Pilot Plant.

In 2009 the DOE established the Used Fuel Disposition Campaign (UFDC) within the Office of Nuclear Energy. The Mission of the UFDC is

To identify alternatives and conduct scientific research and technology development to enable storage, transportation and disposal of used nuclear fuel and wastes generated by existing and future nuclear fuel cycles.

The U.S. national laboratories have participated on these programs and has conducted research and development related to these issues to a limited extent. However, a comprehensive research and development $(R \& D)$ program investigating a variety of geologic media has not been a part of the U.S. waste management program since the mid 1980s. Such a comprehensive R\&D program is being developed in the UFDC with a goal of meeting the UFDC Grand Challenge.

To provide a sound technical basis for absolute confidence in the safety and security of long-term storage, transportation, and disposal of used nuclear fuel and wastes from the nuclear energy enterprise.

The DOE has decided to no longer pursue the development of a repository at Yucca Mountain, Nevada. Since a repository site will ultimately have to be selected, sited, characterized, designed, and licensed, other disposal options must now be considered. In addition to the unsaturated volcanic tuff evaluated at Yucca Mountain, several different geologic media are under investigation internationally and preliminary assessments indicate that disposal of used nuclear fuel and high level waste in these media is feasible. Considerable progress has been made in the U.S. and other nations in understanding disposal concepts in different geologic media, but gaps in knowledge still exist.

A principal aspect of concern to the UFDC as it considers the broad issues of siting a repository in different geologic media are the marked differences in the regulatory bases for assessing suitability and safety of a repository between the U.S. and other nations. Because the probability based - risked informed nature of the current U.S. regulations for high-level radioactive waste and spent nuclear fuel is sufficiently different from other regulations, information gained in previous studies, while useful, likely need to be supplemented to enable more convincing communication with the public, better defense of the numerical models, and stronger safety cases.

Thus, it was recognized when the UFDC was established that there were readily identified disposalrelated R\&D opportunities to address knowledge gaps.. An effort to document these research opportunities was a key component of Fiscal Year (FY) 2010 engineered system, natural system, and system-level modeling activities for a range of disposal environments. A principal contribution to identifying these gaps was a workshop held to gather perspectives from experts both within and external to the UFDC regarding R\&D opportunities.

In the planning for FY2010 it was expected that these activities would culminate with a UFDC research and development roadmap that would identify the knowledge gaps, discuss the R\&D needed to fill these gaps, and prioritize the proposed R\&D over both the near- and long-term. A number of knowledge gaps and needed R\&D were identified and are discussed in this report. However, these preliminary R\&D topics have not been evaluated in detail nor have they been prioritized to support future planning efforts. 
This will be completed in FY11 and the final UFDC Research and Development Roadmap will be completed.

This report discusses proposed $R \& D$ topics in three areas related to repository siting, design, and performance: natural systems, engineered systems, and overall disposal system. The intent of this report is to consolidate the proposed $R \& D$ topics to support subsequent discussions among UFDC and external expertise to identify additional R\&D needs and to prioritize these needs, leading to the development for the UFDC Research and Development Roadmap. 


\section{CONTENTS}

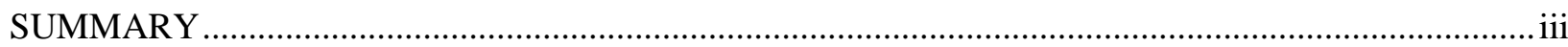

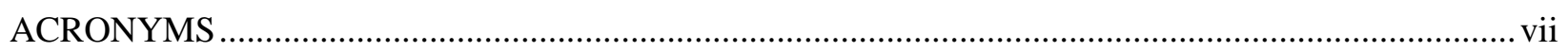

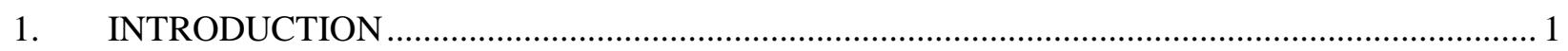

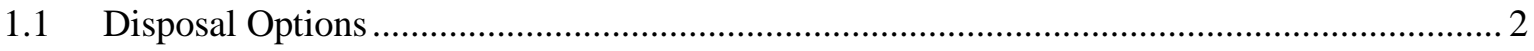

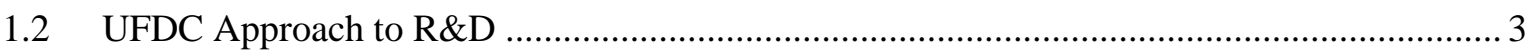

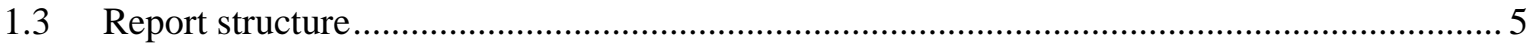

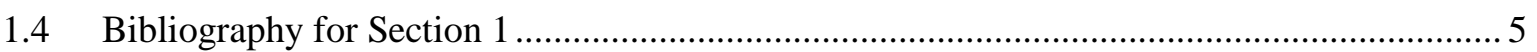

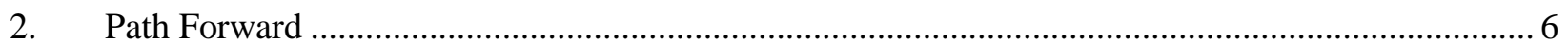

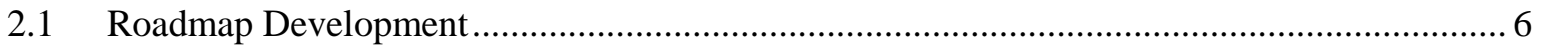

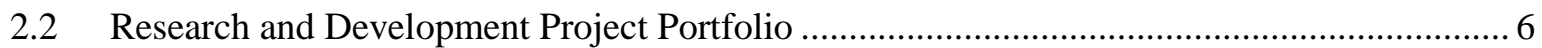

2.2.1 Identification of the Decision Roadmap and the UFDC Decision Timeline................ 6

2.2.2 Identification of the Information Needs for Each Major Decision ............................. 7

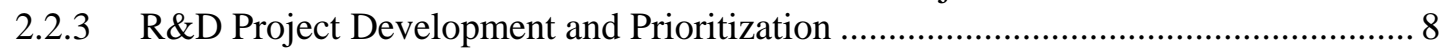

2.2.4 Implementation of the UFDC R\&D Prioritization Approach ................................... 9

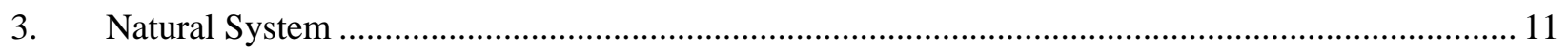

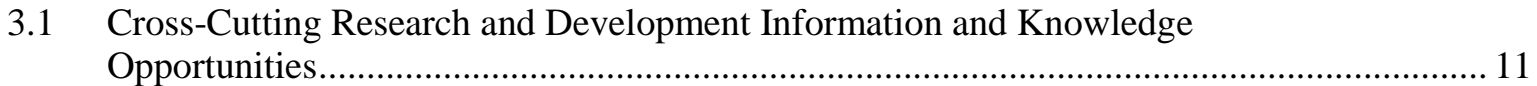

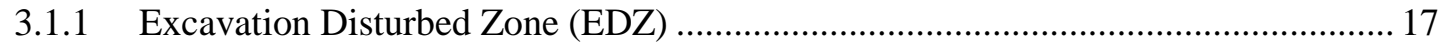

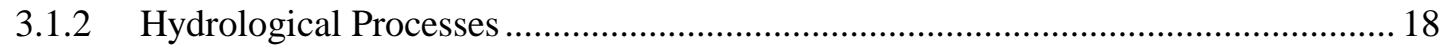

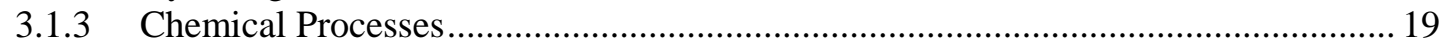

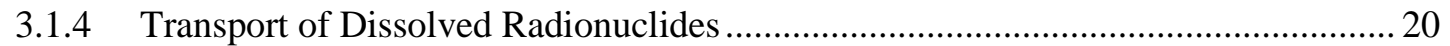

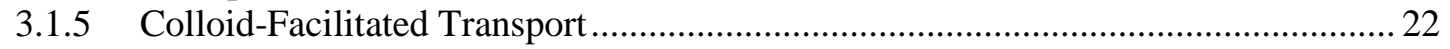

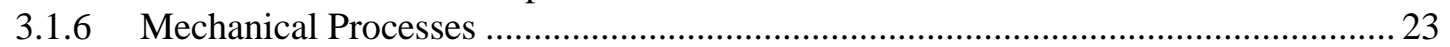

3.2 Research and Development Information and Knowledge Opportunities Gaps

Specific to Individual Disposal Environments........................................................................ 24

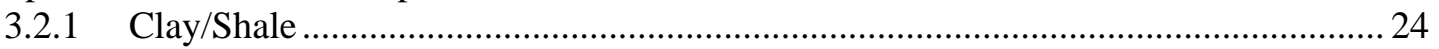

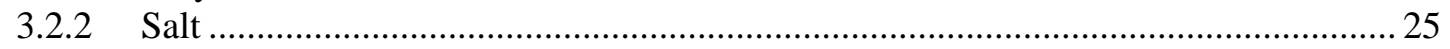

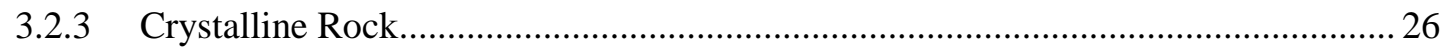

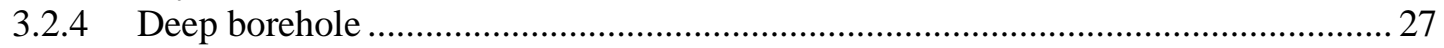

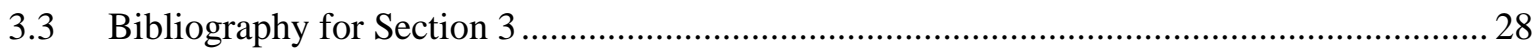

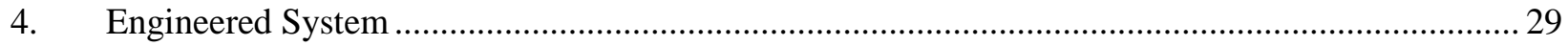

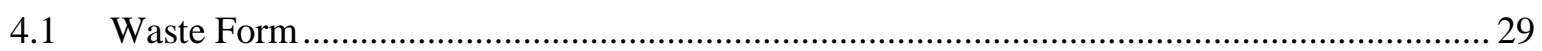

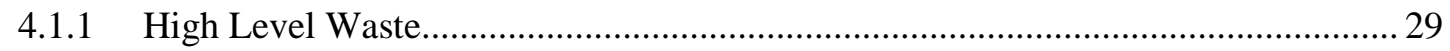

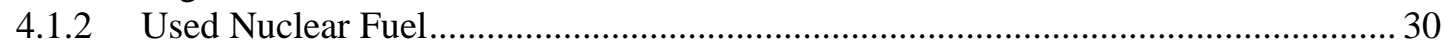

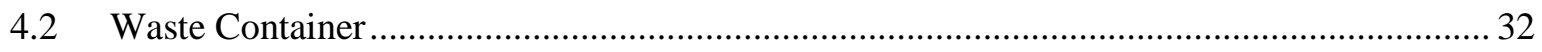

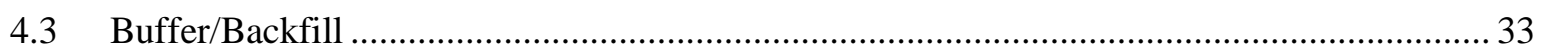

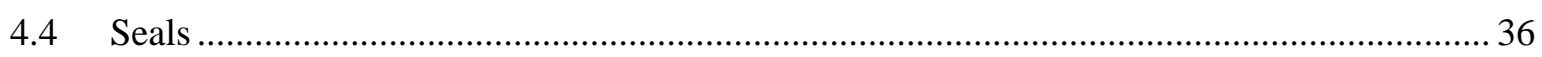

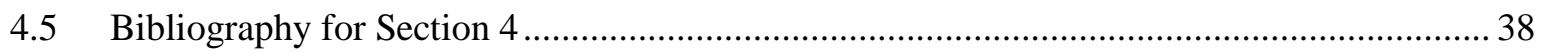

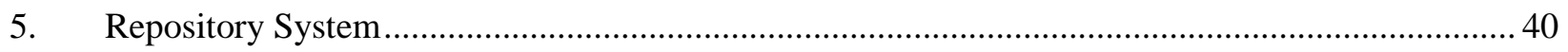




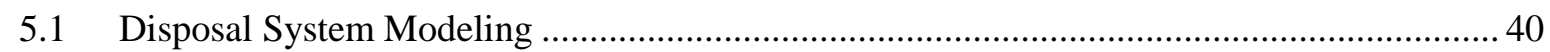

5.2 Operations-Related Research and Technology Development........................................... 41

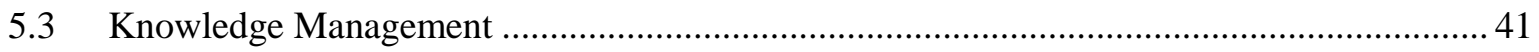

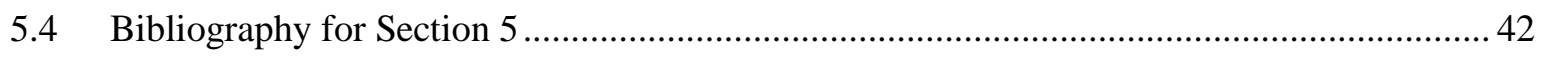

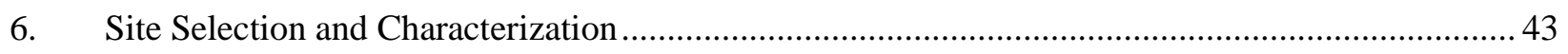

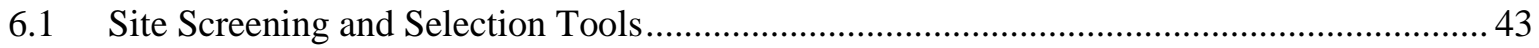

6.2 Experimental and Analytic Techniques for Site Characterization ...................................... 43

6.3 Underground Research Laboratories.......................................................................... 44

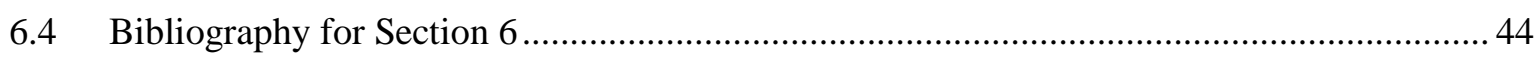

\section{FIGURES}

Figure 1. Components of a Generic Disposal System...........................................................................

Figure 2. Used Fuel Disposition Decision Timeline .............................................................................

Figure 3. UFDC and NEAMS Disposal System Model Development Activities.................................... 40

\section{TABLES}

Table 1. Natural Systems Preliminary Gap Analysis.......................................................................... 12

Table 2: Foreign Underground Research Laboratories ..................................................................... 45 


\section{ACRONYMS}

\begin{tabular}{|c|c|}
\hline BRIE & Bentonite-Rock Interaction Experiment \\
\hline CFT & Colloid Facilitated Transport \\
\hline CRT & Canister Retrieval Test \\
\hline DFN & Discrete Fracture Network \\
\hline $\mathrm{DHC}$ & Delayed Hydride Cracking \\
\hline DOE & U.S. Department of Energy \\
\hline DOE-NE & U.S. Department of Energy, Office of Nuclear Energy \\
\hline DSEF & Disposal Systems Evaluation Framework \\
\hline EBS & Engineered Barrier System \\
\hline EDL & Electric Double Layer \\
\hline EDZ & Excavation Damage Zone \\
\hline EM & U.S. Department of Energy Office of Environmental Management \\
\hline FEP & Feature, Event, and Process \\
\hline FF & Far Field \\
\hline FY & Fiscal Year \\
\hline GDSE & Generic Disposal System Environment \\
\hline $\mathrm{HE}$ & Hydride Embrittlement \\
\hline HLW & High Level Waste \\
\hline IPSC & Integrated Performance and Safety Code \\
\hline LWR & Light Water Reactor \\
\hline NBS & Natural Barrier System \\
\hline NEAMS & Nuclear Energy Advanced Modeling and Simulation program \\
\hline NF & Near Field \\
\hline NWPA & Nuclear Waste Policy Act \\
\hline OFCT & U.S. Department of Energy, Office of Nuclear Energy, Office of Fuel Cycle Technology \\
\hline $\mathrm{R} \& \mathrm{D}$ & Research and Development \\
\hline SCC & Stress Corrosion Cracking \\
\hline SEM & Scanning Electron Microscopy \\
\hline SNF & Spent Nuclear Fuel \\
\hline TBT & Thermal Bentonite Test \\
\hline THCMBR & Thermal-Hydrologic-Chemical-Mechanical-Biological-Radiological Processes \\
\hline THM & Thermal-Hydrologic-Mechanical Processes \\
\hline THMC & Thermal-Hydrologic-Mechanical-Chemical Processes \\
\hline TRISO & Tristructural Isotropic \\
\hline UFDC & Used Fuel Disposition Campaign \\
\hline UNF & Used Nuclear Fuel \\
\hline URL & Underground Research Laboratory \\
\hline WIPP & Waste Isolation Pilot Plant \\
\hline XRD & X-ray Diffraction \\
\hline YMP & Yucca Mountain Project \\
\hline
\end{tabular}





\section{USED FUEL DISPOSITION CAMPAIGN UFD RESEARCH AND DEVELOPMENT ROADMAP - FY10 STATUS}

\section{INTRODUCTION}

The U.S. Department of Energy Office of Nuclear Energy (DOE-NE), Office of Fuel Cycle Technology (OFCT) has established the Used Fuel Disposition Campaign (UFDC) to conduct the R\&D activities related to storage, transportation and disposal.

The Mission of the UFDC is

To identify alternatives and conduct scientific research and technology development to enable storage, transportation and disposal of used nuclear fuel and wastes generated by existing and future nuclear fuel cycles.

The U.S. has, for the past twenty-plus years, focused efforts on disposing spent nuclear fuel (SNF) and high level waste (HLW) in a geologic repository at Yucca Mountain Nevada. The recent decision by DOE to no longer pursue the development of that repository has necessitated investigating other geologic media and concepts for the disposal of SNF and HLW that exists today and that could be generated under future fuel cycles. The disposal of SNF and HLW in a range of geologic media has been investigated internationally. Considerable progress has been made by in the U.S and other nations, but gaps in knowledge still exist.

The U.S. national laboratories have participated in these programs and has conducted research and development related to these issues to a limited extent. However, a comprehensive research and development $(R \& D)$ program investigating a variety of geologic media has not been a part of the U.S. waste management program since the mid 1980s. Such a comprehensive R\&D program is being developed in the UFDC with a goal of meeting the UFDC Grand Challenge.

To provide a sound technical basis for absolute confidence in the safety and security of long-term storage, transportation, and disposal of used nuclear fuel and wastes from the nuclear energy enterprise.

A principal aspect of concern to the UFDC as it considers the broad issues of siting a repository in different geologic media are the marked differences in the regulatory bases for assessing suitability and safety of a repository between the U.S. and other nations. Because the probability based - risked informed nature of the current U.S. regulations for high-level radioactive waste and spent nuclear fuel is sufficiently different from other regulations, information gained in previous studies, while useful, likely need to be supplemented to enable more convincing communication with the public, better defense of the numerical models, and stronger safety cases.

The UFDC was initiated in the summer of 2009 and it was recognized that disposal-related R\&D gaps needed to be identified. This effort was a key component of Fiscal Year (FY) 2010 engineered system, natural system, and system-level modeling activities for a range of disposal environments. In addition, a workshop was held to gather perspectives from experts both within and external to the UFDC regarding R\&D needs.

It was expected that the FY 2010 activities would culminate with a UFDC research and development roadmap that would identify the knowledge gaps, discuss the R\&D needed to fill these gaps, and prioritize the proposed R\&D over both the near- and long-term. A number of knowledge gaps and 
associated R\&D were identified and are discussed herein. However, these R\&D needs have not been evaluated as to whether they are truly necessary nor have they been prioritized to support future planning efforts. This will be done in FY11 and the final UFDC Research and Development Roadmap will be completed.

\subsection{Disposal Options}

The UFDC is currently evaluating the viability of four main disposal options for high-level radioactive waste and spent fuel: mined repositories in three geologic media (salt, shale, and crystalline), and the use of deep borehole in crystalline rocks. (For each of these disposal options, the rock type is identified at a broad level. Thus, salt includes both bedded and domal rocks, clay includes a broad range of fine-grained sedimentary rocks including shales, argillites, and claystones as well as soft clays, and granite includes a range of related crystalline rocks.)

These disposal options are not presented as a final list of the best possible alternatives, and the DOE recognizes that other options have been identified in the past that also have the potential to provide safe long-term isolation, including, for example, sub-seabed disposal and the mined repository in volcanic tuff at Yucca Mountain. As other disposal concepts are identified that warrant further investigation they will be evaluated.

There are multiple bases for focusing on these four main concepts at this stage of the program.

First, the U.S. went through an extensive review of all available options for disposal and management during the 1970s, culminating in the 1980 Environmental Impact Statement on Management and Disposal of Commercially Generated Radioactive Wastes (DOE/EIS-0046). This review considered a full range of alternatives to mined geologic repositories, including deep boreholes, sub-seabed disposal, space disposal, and ice sheet disposal. Mined repositories were the favored option, but sub-seabed disposal and deep boreholes were retained for further consideration. Sub-seabed disposal remained technically a promising option, but was precluded by international treaty in the 1990s. Deep boreholes were considered to require further technological advances, and disposal programs in both the U.S. and other nations focused on mined repositories beginning in early 1970s. The U.S. program evaluated salt, granite, shale, basalt (at the Hanford site), and volcanic tuff at Yucca Mountain before focusing exclusively on volcanic tuff as a result of the 1987 Nuclear Waste Policy Amendments Act.

Second, conclusions drawn in the U.S. program in the early and mid 1980s about the potential viability of salt, granite, and clay as disposal media have been confirmed by extensive work internationally. Granite repository concepts have been evaluated in detail in Sweden, Finland, Switzerland, and Japan. Clay disposal concepts have been evaluated in detail in France, Belgium, and Switzerland. Salt has been shown to be a viable medium for disposal of non-heat-generating transuranic waste at the Waste Isolation Pilot Plant in the U.S., and research in Germany continues to show promise for the disposal of heatgenerating waste in salt. Other geologic media are under consideration for specific purposes (e.g., Canada is investigating the use of a mined repository in carbonate rocks to dispose of intermediate level waste, and the U.S. has disposed of low-level and transuranic waste in near-surface alluvium).

Third, deep borehole disposal continues to be the primary viable alternative to mined repositories. DOE investigated the concept in the 1990s for the disposal of surplus plutonium, and studies have continued at Sheffield University in the United Kingdom, in the Swedish high-level waste program, at MIT, and at Sandia National Laboratories in the U.S. 
Finally, no new information has been developed since the early 1980s to suggest that options evaluated and screened from further consideration at that time (e.g., space disposal or ice-sheet disposal) should be re-evaluated.

\section{$1.2 \quad$ UFDC Approach to R\&D}

The research and development conducted by the UFDC aims to improve the safety case for geologic disposal. In this context, the UFDC uses the international definition of the safety case (NEA 2004):

A safety case is the synthesis of evidence, analyses and arguments that quantify and substantiate a claim that the repository will be safe after closure and beyond the time when active control of the facility can be relied on. The safety case becomes more comprehensive and rigorous as a programme progresses, and is a key input to decision making at several steps in the repository planning and implementation process. A key function of the safety case is to provide a platform for informed discussion whereby interested parties can assess their own levels of confidence in a project, determine any reservations they may have about the project at a given planning and development stage, and identify the issues that may be a cause for concern or on which further work may be required.

A detailed safety case, presented in the form of a structured set of documents, is typically required at major decision points in repository planning and implementation, including decisions that require the granting of licenses. A license to operate, close, and in most cases even to begin construction of a facility, will be granted only if the developer has produced a safety case that is accepted by the regulator as demonstrating compliance with applicable standards and requirements. Less detailed technical evaluations and safety assessments may be adequate to support some levels of internal planning and decision making by the developer. Crucially, the discipline of preparing a safety case, and presenting the case for scientific and technical review, regulatory review or wider non-technical reviews, ensures that post-closure safety is explicitly and visibly considered at each project stage.

The UFDC is utilizing performance assessment concepts to inform and guide development of disposal related R\&D projects: the identification of features, events, and processes (FEPs) potentially relevant to the performance of a range of possible disposal system alternatives under consideration, the identification of gaps in knowledge about those FEPS, with R\&D targeted towards better understanding of those FEPS considered to be FEPs most critical to understanding system performance.

A FEP generally encompasses a single phenomenon; typically it is a process or event acting upon a feature. Applied to the range of disposal system alternatives (i.e., combinations of disposal concepts, waste form types, engineered designs, and geologic settings) under consideration, FEP analysis includes:

- FEP identification - development of a comprehensive list of phenomena potentially relevant to the range of disposal system alternatives

- FEP screening - evaluation of relevance and importance of each phenomenon to each disposal system alternative with respect to the safety case

- FEP implementation - mathematical representation of important phenomena in a performance assessment (PA) model

The end result of this process is a listing of FEPs and their potential important to the performance of the disposal system / disposal environments and the overall safety case for each disposal environment. The current knowledge base can be mapped to corresponding FEPs to identify any gaps in knowledge.

Potential information gaps, and hence research opportunities, lie in the areas of the data underlying, the representativeness of, confidence in, and defensibility of the mathematical representation of important 
phenomena in a safety assessment model used to support the safety case. An appropriate approach to identifying and prioritizing the importance of these information gaps is through system-level modeling which can then be used to evaluate the importance of these gaps with respect to overall disposal system performance. This results in a risk-informed prioritization of $R \& D$ needs where the results can be used to prioritize R\&D projects towards the most critical knowledge gaps.

The content and categorization of the UFDC FEP list derives from FEP identification and categorization efforts cataloged in the International FEP Database maintained by the Nuclear Energy Agency (NEA). The NEA FEP Database contains FEPs from radioactive waste disposal programs in Belgium, Canada, Sweden, Switzerland, USA (WIPP), and the UK. The UFDC FEP list also includes FEP information developed as part of the Yucca Mountain Project (YMP).

Figure 1 shows a conceptualization of a generic radioactive waste disposal system that includes design components, physical domains, and phenomena that are likely to be common across the range of possible UFDC disposal system alternatives.

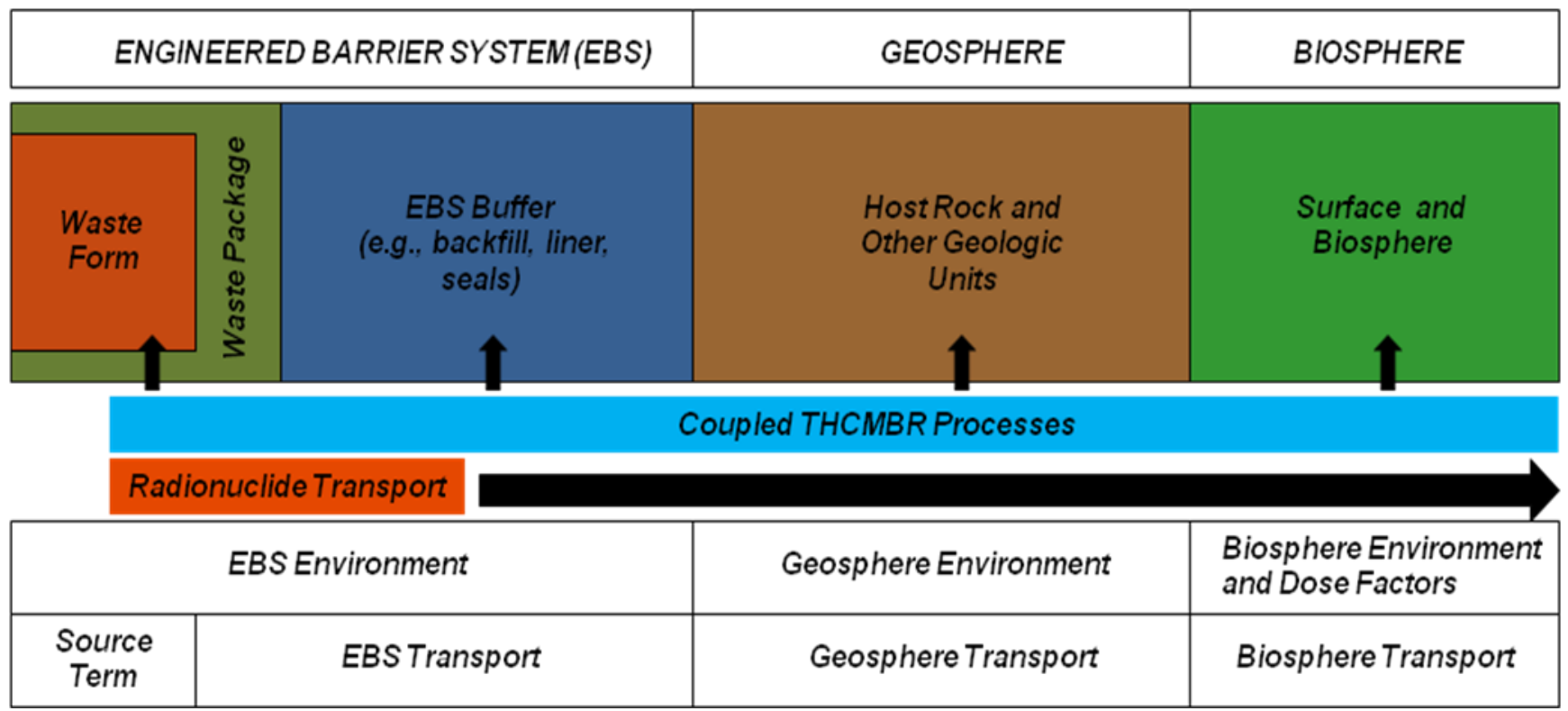

Figure 1. Components of a Generic Disposal System

The top half of Figure 1 shows the three physical domains of the generic disposal system: the engineered system, and the natural system consisting of both the geosphere and the biosphere. Each of these three domains contains sub-domains: waste form, waste package, and engineered buffer; host rock and other geologic units for the geosphere; and the land surface for the biosphere. The bottom half of Figure 1 shows the phenomena that can affect each of these domains and sub-domains. These phenomena include, at a high level, the coupled thermal-hydrologic-chemical-mechanical-biological-radiological (THCMBR) processes that describe (1) waste form degradation and the source term, (2) radionuclide transport through the engineered system, (3) radionuclide transport through the host rock and surrounding geologic units (i.e., the geosphere), and (4) radionuclide transport and health effects in the biosphere. In addition to their direct effects on radionuclide transport, the coupled THCMBR processes also influence the physical and chemical environments in the engineered system, geosphere, and biosphere, which in turn affect radionuclide transport. 
The physical domains and sub-domains and phenomena in Figure 1 are presented at a very high level. The UFDC FEP list provides additional detail regarding these domains and phenomena.

\section{$1.3 \quad$ Report structure}

This report contains four broad sections that discuss knowledge gaps and associated R\&D topics identified in the natural system, engineered system, repository system, and site characterization areas. Potential R\&D topics within each of these broad areas are identified and summarized. Prior to discussing the potential R\&D topics, the path forward for developing the R\&D Roadmap and prioritizing R\&D activities is discussed.

\subsection{Bibliography for Section 1}

Nuclear Energy Agency, "Post-Closure Safety Case for Geological Repositories, Nature and Purpose," 2004, ISBN 92-64-02075-6. 


\section{Path Forward}

This report presents a status report in the development of the UFDC Disposal Research and Development Roadmap. The roadmap will be completed in Fiscal Year 2011 and will be used to prioritize projects for the remainder of that fiscal year, to support any revision to the Campaign Implementation Plan, and to support future planning efforts. Completion of the roadmap requires follow-on review of the potential research and development needs discussed above, identification of additional research and development needs, establishment of a decision process for evaluating the research and development projects against these needs, and the development of a portfolio of projects.

\subsection{Roadmap Development}

This report will be provided to UFDC principal investigators and other experts in the field of radioactive waste disposal for their review. A workshop will be held in early Fiscal Year 2011 to obtain feedback on this report and solicit additional R\&D needs that may not have been identified in this report. A decision framework, discussed in Section 6.2, will be developed to evaluate the list of R\&D needs to establish research priorities. These needs and their respective priorities will be documented in the final UFDC Research and Development Roadmap.

\subsection{Research and Development Project Portfolio}

The approach described below for prioritizing R\&D activities combines both the existing "bottom-up" identification of research questions and projects with the development of a "top-down" definition of UFDC research needs. The top-down structure starts with the identification of the key decisions that the $\mathrm{R} \& \mathrm{D}$ program is intended to support, with a goal of identifying and prioritizing projects that will provide the information required to support those decisions, at the time the decisions have to be made.

The UFDC has fundamentally a research and technology development mission, but that R\&D is to be focused on information and technologies that will enable the ultimate disposal of nuclear fuel and wastes. While there is a great deal of uncertainty about what the ultimate disposal approach will be, and about the timeline for which decisions about disposal will be made, it is clear that there is a series of decisions that must be made, at a variety of levels, to "enable storage, transportation and disposal." The UFDC will be most effective if resources, research, and technology development are targeted to provide information and capabilities that will be required as input to each of those key decisions.

The following sections describe three key steps in developing a "top down," decision-oriented roadmap that will be implemented for UFDC. Each of these steps will be developed further with UFDC management, technical staff, and perhaps with other relevant policy experts.

\subsubsection{Identification of the Decision Roadmap and the UFDC Decision Timeline}

Although there is significant regulatory and technical uncertainty about what the national solution to disposal of used nuclear fuel and wastes will be, there is fairly clear set of decisions that must be made to get from today to safe and secure disposal. Obviously, R\&D will be most useful when it:

- Provides information that decision-makers need to have for each key decision, at the time those decisions must be made.

- Enables immediate execution or initiation of actions that move the nation closer to safe and secure disposal as soon as each of those key decisions is made. 
In other words, the program should aim to provide all the information decision makers need, and to provide the capability to execute those decisions as soon they are made.

The first step in developing a decision-oriented R\&D program is to identify and understand the decision roadmap and timeline. Under the current political and regulatory environment, the precise timeline is highly uncertain, but the basic type and order of the major decisions can be developed by reviewing the current governing regulations, the ongoing work of the 'Blue Ribbon Commission for America's Nuclear Future," the history of the Yucca Mountain and WIPP programs, and the progression of decisions in other countries as they evaluate and develop geologic disposal programs. Policy, regulatory, and technical decisions will all need to be made in order, as suggested in the notional UFDC Decision Timeline shown in Figure 2.

An overarching theme that applies across the decision timeline is the safety case for geologic disposal, both during the operational period (pre-closure) and following closure of a repository (post-closure). The safety case evolves through each decision point along the timeline and the R\&D conducted must support the development of a safety case.

The UFDC Decision Timeline will be developed and documented in the UFDC Disposal Research and Development Roadmap.

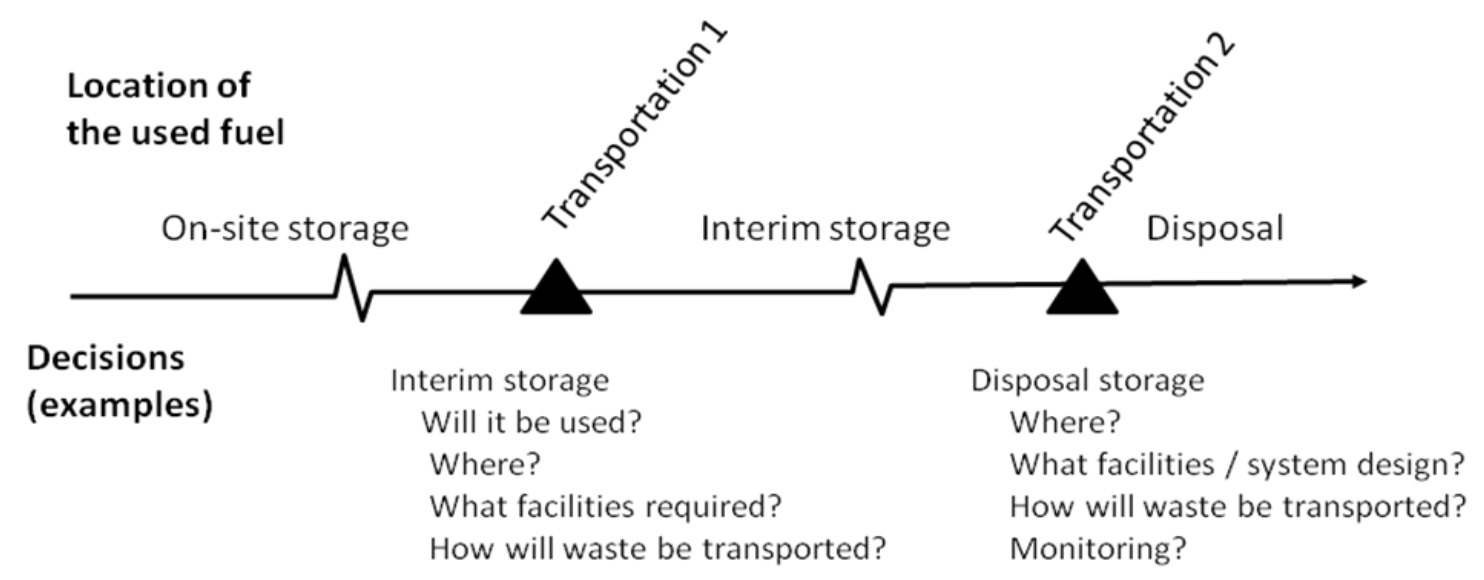

Siting, design, security and safety assessment

(different levels and types of information are necessary at different stages in the process)

Site identification

Site screening or prioritization

Disposal system design for selected sites - initial design concepts and viability

Detailed design and evaluation of security and safety

Demonstration of security and safety

Construction and disposal of waste

Monitoring

Figure 2. Used Fuel Disposition Decision Timeline.

\subsubsection{Identification of the Information Needs for Each Major Decision}

The next step is slightly more complex, and requires some professional judgment to identify, for each major decision that must be made, the information that will help the relevant decision makers understand 
and evaluate their options. This is a key step in the process; in essence, determining what those information needs is tantamount to determining what should drive the R\&D program. Different types and different levels of information will be necessary at different times. Several examples follow.

- The sections above discuss R\&D needs related to the engineered and natural systems along with the total repository system. The conduct of the R\&D to meet these needs should be evaluated against their importance within an overall safety case using the FEPs approach and considering the UFDC decision timeline.

- Early in the process there is likely to be a need to identify possible locations for a disposal facility, and potentially for an interim storage facility. Identifying characteristics that make a site more or less promising would be useful in evaluating candidate sites; whether those criteria should focus on identifying "disqualifying" characteristics or desirable characteristics may depend on policy decisions about how site identification is to be done (e.g., a volunteer process, a technical suitability screening, or some combination).

- Engineering designs of the disposal (or storage) system will ultimately need to be detailed and specific for any location where such facilities might be located. Prior to selection of one or more "final" locations, however, it will likely be necessary to develop and evaluate alternative engineering designs for each location at a less detailed level, but still with sufficient detail to determine the most suitable combination of design and location from a technical perspective. Even very early in the process it may be useful to be able to quickly evaluate a set of design concepts for any potential site.

Completion of the UFDC Disposal Research and Development will require the identification of a comprehensive set of information needs required at each time step, broadly framed around supporting the safety case.

\subsubsection{R\&D Project Development and Prioritization}

The decision timeline and the information needed to support each decision taken together provide a clear picture of what the program's research and technology development needs are, and will be used to define the UFDC Disposal Research and Development roadmap. The completed roadmap will be used in several ways:

- To evaluate proposed R\&D projects. Projects should all be evaluated in terms of the decisions they can help support or execute, and the timing and level of information anticipated relative to the decision needs.

- To identify high priority $R \& D$ areas for which projects should be developed. These might include projects to support near-term decisions, projects which will produce information that can be used to support multiple decisions, projects which will provide critical information for later decisions but which require a relatively long time to yield that information, and so on.

- To modify or refocus existing projects to ensure that they produce the "right" level of information at the necessary time.

In developing the overall UFDC R\&D program roadmap and projects, UFDC will also consider the full portfolio of projects and their interactions. Portfolio level criteria may include items such as:

- Both short-term and long-term projects are included

- Projects that have positive synergies with other ongoing work 
- Includes projects that address issues related to locations, to system designs, and to the interaction of location and designs

- Includes projects related to understanding the physical site (natural systems) and the engineered components and performance

- Some high-risk, high-payoff projects as well as low-risk ones

- Consideration of the external benefits, beyond support for UFDC decisions

Specifically, any proposed UFDC R\&D project should clearly identify the data and information that the work is intended to produce, how it relates and contributes to the evolving safety case, and the expected time that the information will be available. Investigators should also describe the decisions that might benefit from having their research results and how that information might be used in decision support.

UFDC management can then use that information to ensure that the R\&D priorities are appropriately linked to decision needs. The perspectives of the technical staff and those proposing R\&D projects will be useful in developing the decision roadmap and decision/information needs mapping described above.

Completion of the UFDC Disposal Research and Development Roadmap will involve the development of portfolio level criteria that will be used to evaluate $R \& D$ projects for merit.

\subsubsection{Implementation of the UFDC R\&D Prioritization Approach}

The approach for evaluating existing proposal for UFDC R\&D projects will be developed in consultation with the UFDC project management team. Based on the OCRWM ST\&I process, a process that looks like the following is envisioned.

\begin{tabular}{|l|} 
Phase 1: \\
Decision \\
relevance
\end{tabular}$\rightarrow \begin{gathered}\text { Phase 2: } \\
\text { Technical merit \& } \\
\text { decision support }\end{gathered} \longrightarrow \begin{gathered}\text { Phase 3: } \\
\text { Portfolio } \\
\text { considerations }\end{gathered}$

\section{UFDC Management Decision Making}

While the UFDC intends to use a formal process for establishing R\&D priorities, it must be recognized that the UFDC management can and should have flexibility to establish priorities and direct R\&D activities outside this formal process. The establishment and execution of such a formal process takes time and UFDC management may at times have to make decisions quickly. The formal process described herein will inform and support UFDC management decisions.

\section{Phase 1}

Determine the decisions that could make use of information the research is intended to generate. As an example, researchers proposing projects would be asked to identify how the research will be used to support one of the following types of decision(s), as described above:

- Site identification

- Site screening and prioritization

- Disposal system design 
- Evaluation of site \& system safety and performance

If the proposed research supports a UFDC-related decision other than these listed, that decision should be described. Any decisions identified in this process will be carried forward to the development of the longer-term "top-down" process as described above.

\section{Phase 2}

Evaluate the technical merit of proposed work and the degree to which it will improve decision making. This step requires two related evaluations. First is a traditional evaluation of the technical merits of the proposed work. Technical merit includes evaluation of the quality of the research proposal and research team and the likelihood that the work will achieve it technical objectives. The technical evaluation may also consider synergies among the proposals and, if relevant, benefits that the work could provide outside the UFDC program.

The second evaluation will focus on the research timing and anticipated results relative to decision needs and the safety case. Research timing must align with the UFDC Decision Timeline, so that results will be available at the time they are needed. In addition, the most beneficial research will be that which addresses information needs that are absolutely critical to the decisions being made and to the safety case. The potential impact of the research on the decision should be identified and discussed explicitly: does it produce information without which sound and defensible decision making is not possible? Or does it produce information that will increase confidence in those decisions, but without which technically defensible decisions can still be made? The answers to these questions will help UFDC management ensure that the program focuses on research and development that will be most useful throughout the decisions process.

For the interim process both of these evaluations should be conducted by the UFDC management team; in future evaluations it may be beneficial to include outside technical review, and potentially to include decision-makers outside of the UFDC program in the evaluation of the decision relevance of the work.

$\underline{\text { Phase } 3}$

The finals step is to assemble a set of research projects that address the appropriate range of decision support needs, using the portfolio level criteria identified above to develop the portfolio of R\&D projects. 


\section{Natural System}

This section identifies research and development gaps within the natural system for the generic geologic media under consideration by the UFDC. Cross-cutting R\&D gaps applicable to all media are first presented followed by R\&D gaps specific to each geologic media. A preliminary R\&D gap analysis for the natural system is shown in Table 1 . This table is an initial effort at identifying potential R\&D needs. Future activities will further refine this list and prioritize the needs for focused R\&D. The column for site characterization intends to indicate the data needs for a specific site, which are beyond the scope of the current UFDC program which is conducting R\&D on generic disposal environments.

\subsection{Cross-Cutting Research and Development Information and Knowledge Opportunities}

This section presents cross-cutting research and development topics that address knowledge gaps potentially applicable to all generic geologic media under consideration by the UFDC. The areas discussed include:

- Excavation disturbed zone (EDZ)

- Hydrological processes

- Chemical processes

- Transport of dissolved radionuclides

- Colloid-facilitated transport

- Mechanical processes

All repository performance evaluations require suitable numerical models to be used in repository design and performance assessment analyses. State-of-the-art modeling can be supported by defining a benchmark modeling efforts and using the best available technology for comparative assessments. Such benchmark modeling could begin with experiments already conducted, and could be developed in concert with international coworkers. Results of these benchmark studies allow evaluation of computational capabilities, make use of ongoing laboratory research and inform potential design and analysis. Such benchmarking could be applied to all natural system areas discussed below. 
Table 1. Natural Systems Preliminary Gap Analysis

\begin{tabular}{|c|c|c|c|c|}
\hline \multirow[b]{2}{*}{ Category } & \multirow[b]{2}{*}{ Issues } & \multicolumn{3}{|c|}{ Gaps } \\
\hline & & $\begin{array}{c}\text { Site } \\
\text { characterization }\end{array}$ & Model & Data \\
\hline \multirow{10}{*}{ General } & Underestimated performance of natural system barrier & $\mathrm{x}$ & $\mathrm{x}$ & $\mathrm{x}$ \\
\hline & Natural system impact on repository construction \& design & $\mathrm{x}$ & $\mathrm{x}$ & $\mathrm{x}$ \\
\hline & $\begin{array}{l}\text { Geophysical techniques for far-field characetrization (e.g., horizontal and vertical reflectors, } \\
\text { tomography) }\end{array}$ & $\mathrm{x}$ & & \\
\hline & Flexible integrated disposal system model with interfaces to fuel cycle & & $\mathrm{x}$ & $?$ \\
\hline & Upscaling issue of both characterization and mathematical model & $\mathrm{x}$ & $\mathrm{x}$ & \\
\hline & Collaboration with DOE-EM, potentially at their sites - Field scale experiments & $\mathrm{x}$ & $\mathrm{x}$ & \\
\hline & Characterization of heterogeneity & $\mathrm{x}$ & $\mathrm{x}$ & \\
\hline & Uncertainty quantification: spatial variability vs. parameter uncertainty & & $\mathrm{x}$ & $\mathrm{x}$ \\
\hline & Effect of "Outliers" Performance assessment results & & $\mathrm{x}$ & \\
\hline & $\begin{array}{l}\text { Compilation of existing data (International, U.S. labs, YMP, WIPP \& others) and data from other } \\
\text { areas (e.g., carbon capture \& sequestration - CSS) }\end{array}$ & & & $\mathrm{x}$ \\
\hline
\end{tabular}


Used Fuel Disposition Research and Development Roadmap - FY10 Status

September 2010

Table 1. Natural Systems Preliminary Gap Analysis (continued)

\begin{tabular}{|c|c|c|c|c|}
\hline \multirow[b]{2}{*}{ Category } & \multirow[b]{2}{*}{ Issues } & \multicolumn{3}{|c|}{ Gaps } \\
\hline & & Site Characterization & Model & Data \\
\hline \multirow{19}{*}{ EDZ } & Complex coupling of processes (physical, chemical, thermal, mechanical) & & $\mathrm{x}$ & $\mathrm{x}$ \\
\hline & Methods for coupled waste form/engineered system/natural system testing/modeling & & $\mathrm{x}$ & $\mathrm{x}$ \\
\hline & Couplings between EBS and NBS. & & $\mathrm{x}$ & $\mathrm{x}$ \\
\hline & $\begin{array}{l}\text { Near- and far-field interface chemistry (perturbation \& transient phenomena, repository operation, } \\
\text { thermal effect) }\end{array}$ & & $\mathrm{x}$ & $\mathrm{X}$ \\
\hline & Gas generation \& its impacts & & $\mathrm{x}$ & $\mathrm{x}$ \\
\hline & Gas displacement and leakage & & $\mathrm{x}$ & $\mathrm{x}$ \\
\hline & Excavation \& ventilation-induced fracturing in clay & & $\mathrm{x}$ & $\mathrm{x}$ \\
\hline & Fracture initiation \& healing (re-compaction as a function of environment) & & $\mathrm{x}$ & $\mathrm{x}$ \\
\hline & Heterogeneity \& anisotropic properties & $\mathrm{x}$ & & \\
\hline & Fast transport pathways bypassing the natural or engineered system & $\mathrm{x}$ & $\mathrm{x}$ & \\
\hline & Coupling between rock mechanics and hydrology & & $\mathrm{x}$ & $\mathrm{x}$ \\
\hline & Technical basis of thermal limits & & $\mathrm{x}$ & $\mathrm{x}$ \\
\hline & Rate of EDZ growth \& healing/compaction & & $\mathrm{x}$ & $\mathrm{X}$ \\
\hline & Geochemical disturbed rock zone & & $\mathrm{x}$ & $\mathrm{x}$ \\
\hline & Criticality (lab data and test protocol, batch vs. flow-thru tests, weakness Kd approach) & & $\mathrm{x}$ & $\mathrm{x}$ \\
\hline & Rock stability \& repository design & $\mathrm{x}$ & $\mathrm{x}$ & $\mathrm{x}$ \\
\hline & Non-destructive monitoring techniques (e.g. acoustic detection) & $\mathrm{x}$ & & \\
\hline & Robust of repository concepts w/r ground motion & $\mathrm{x}$ & $\mathrm{x}$ & \\
\hline & Shaft seal design & & $\mathrm{x}$ & $\mathrm{x}$ \\
\hline \multirow{9}{*}{$\begin{array}{l}\text { Hydrologic } \\
\text { Processes }\end{array}$} & Fracture flow and discrete fracture representations & $\mathrm{x}$ & $\mathrm{x}$ & $\mathrm{x}$ \\
\hline & Avoid too conservative assumptions & & $\mathrm{x}$ & \\
\hline & Single well tracer injection test & & & \\
\hline & Long term well injection tests & $\mathrm{x}$ & & \\
\hline & Develop inverse modeling capability for characterization of hydro-DFN (international collaboration) & & $\mathrm{x}$ & \\
\hline & Disruptive event-driven overpressures in far field & $\mathrm{x}$ & $\mathrm{x}$ & $\mathrm{X}$ \\
\hline & Knowledge of cap rocks in CSS (salt formation can also be a cap rock) & $\mathrm{x}$ & $\mathrm{x}$ & $\mathrm{x}$ \\
\hline & Possible advective flow path on large scale, long term & $\mathrm{x}$ & $\mathrm{x}$ & \\
\hline & Impacts of climate change on groundwater recharge & $\mathrm{x}$ & $\mathrm{x}$ & $\mathrm{x}$ \\
\hline
\end{tabular}


Table 1. Natural Systems Preliminary Gap Analysis (continued)

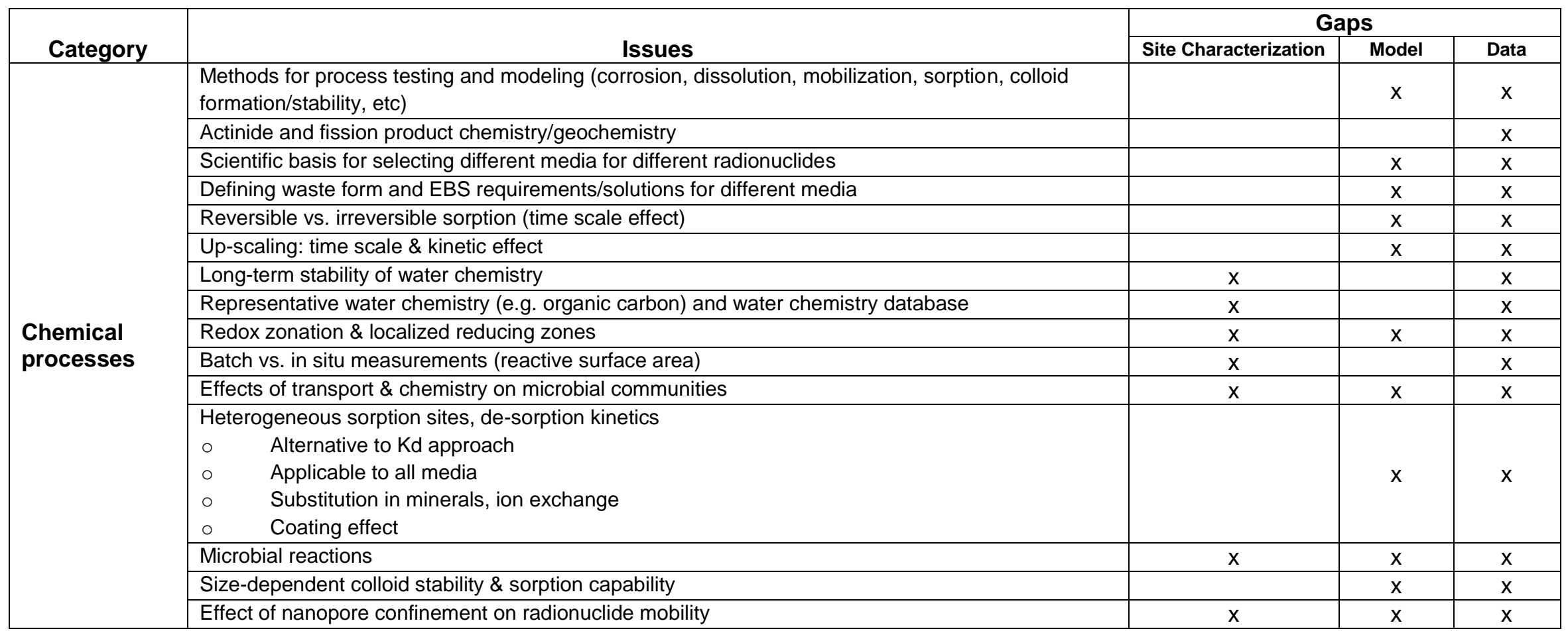


Used Fuel Disposition Research and Development Roadmap - FY10 Status

September 2010

Table 1. Natural Systems Preliminary Gap Analysis (continued)

\begin{tabular}{|c|c|c|c|c|}
\hline \multirow[b]{2}{*}{ Category } & \multirow[b]{2}{*}{ Issues } & \multicolumn{3}{|c|}{ Gaps } \\
\hline & & Site Characterization & Model & Data \\
\hline \multirow{15}{*}{$\begin{array}{l}\text { Transport } \\
\text { processes }\end{array}$} & Effect physical and chemical heterogeneity & $\mathrm{x}$ & $\mathrm{x}$ & $\mathrm{x}$ \\
\hline & $\begin{array}{l}\text { Improve flow and radionuclide transport modeling } \\
\text { Discrete fracture network model } \\
\circ \\
\text { Methods for characterizing sparse fracture networks } \\
\text { Moving beyond the use of representative waste package modeling approach to full } \\
\text { representation of repository geometry }\end{array}$ & $x$ & $\mathrm{x}$ & $\mathrm{x}$ \\
\hline & $\begin{array}{ll}\text { Improve } \text { understanding of field-scale radionuclide retention } \\
\circ & \text { Laboratory \& field scale experiments } \\
\circ & \text { Integrated modeling and site characterization strategies } \\
\circ & \text { Fractured media and heterogeneous porous media }\end{array}$ & $\mathrm{x}$ & $\mathrm{x}$ & $\mathrm{x}$ \\
\hline & $\begin{array}{ll}\text { Effective diffusion in clay } \\
\circ & \text { Pore size } \\
\circ & \text { Electric double layer (EDL) } \\
\circ & \text { Non-Fickean diffusion }\end{array}$ & $\mathrm{x}$ & $\mathrm{x}$ & $\mathrm{x}$ \\
\hline & $\begin{array}{l}\text { Diffusion processes in different rocks } \\
\circ \text { Other studies on contaminant transport } \\
\circ \quad \text { Diffusion in fractured rocks, up-scaling } \\
\circ \quad \text { Diffusion in salt }\end{array}$ & $\mathrm{x}$ & $\mathrm{x}$ & $x$ \\
\hline & $\begin{array}{l}\text { Experiments at multiple scales with modeling tightly integrated - results at each scale will inform } \\
\text { work at other scales }\end{array}$ & & $\mathrm{x}$ & \\
\hline & $\begin{array}{l}\text { Integrated, multi-disciplinary approach to understanding multi-scale processes controlling } \\
\text { contaminant mobility in the environment }\end{array}$ & $\mathrm{x}$ & $\mathrm{x}$ & $\mathrm{x}$ \\
\hline & Understanding of heterogeneity and coupled processes and how they scale & $\mathrm{x}$ & $\mathrm{x}$ & $\mathrm{x}$ \\
\hline & Heterogeneous in chemistry and flow velocity & $\mathrm{x}$ & $\mathrm{x}$ & $\mathrm{x}$ \\
\hline & Alternative to Kd approach for modeling radionuclide transport & & $\mathrm{x}$ & $\mathrm{x}$ \\
\hline & 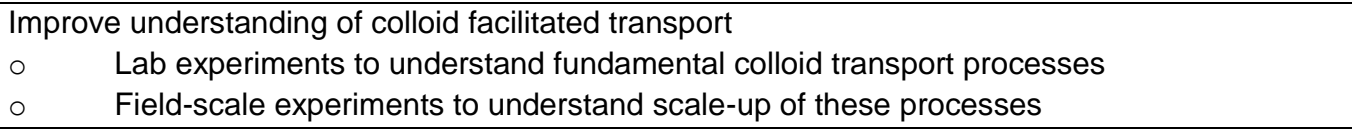 & $\mathrm{x}$ & $\mathrm{x}$ & $\mathrm{x}$ \\
\hline & What colloid type dominates? & $\mathrm{x}$ & & $\mathrm{x}$ \\
\hline & Can colloid transport enough Pu to be significant & & $\mathrm{x}$ & $\mathrm{x}$ \\
\hline & Organic colloids & $\mathrm{x}$ & & $\mathrm{x}$ \\
\hline & $\begin{array}{l}\text { Focus on transport of radionuclide classes in the natural system largely decouples R\&D program } \\
\text { from waste stream and waste form considerations }\end{array}$ & & $\mathrm{x}$ & $\mathrm{x}$ \\
\hline
\end{tabular}


Table 1. Natural Systems Preliminary Gap Analysis (continued)

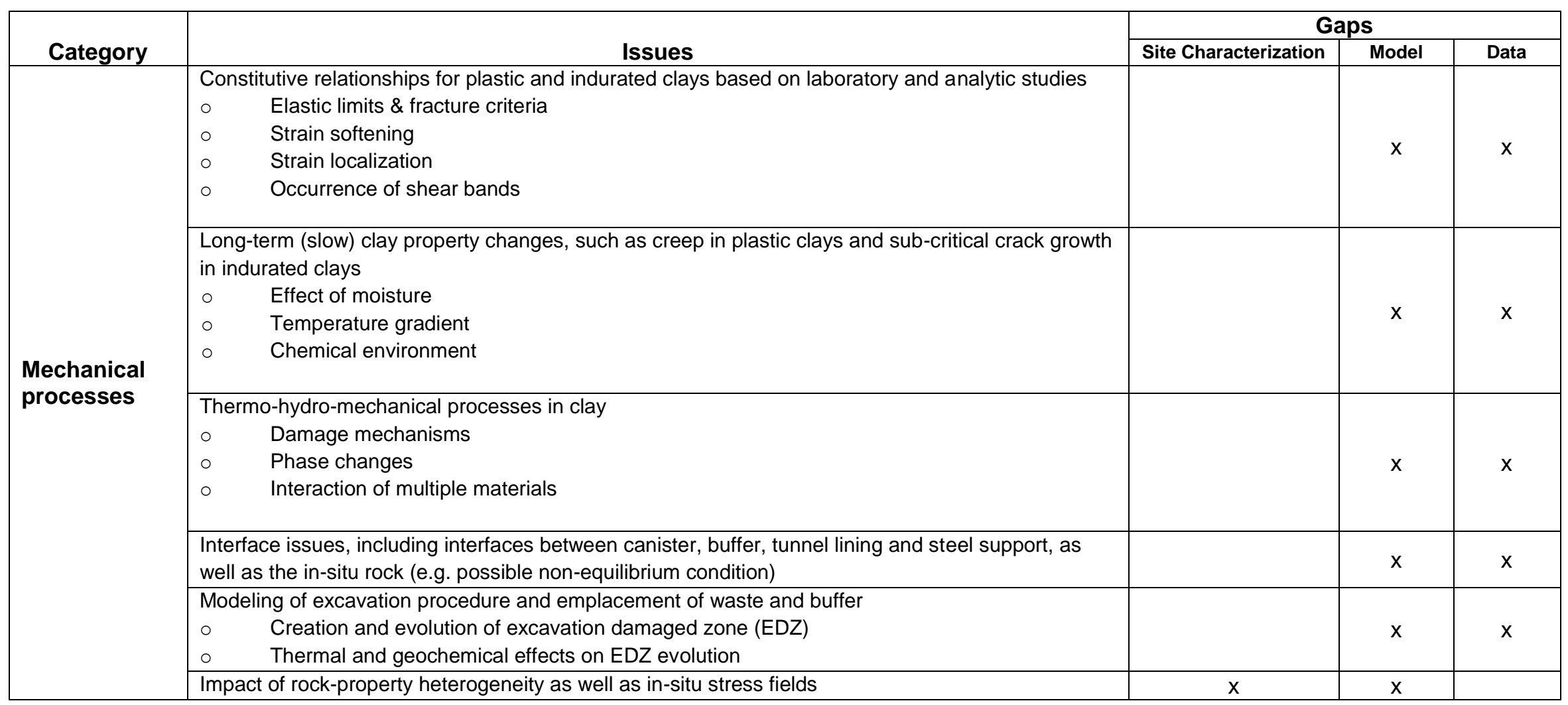




\subsubsection{Excavation Disturbed Zone (EDZ)}

One of the most widely discussed aspects of repository host rock regardless of lithology is the damage caused by excavation. The EDZ is created by changes to the preexisting stress state and is a function of the material properties in relation to the stress conditions. Fractures have an appreciable effect on the permeability of the host rock and therefore their extent and characteristics are important to quantify. In addition for clay/shale media, the EDZ is also influenced by near-field desaturation and dessication that may lead to local fracturing and material weakening. A repository rock (such as shale or salt) that has the capacity to re-seal or heal fractures in the EDZ could be highly desirable for isolation purposes. The impact of tunnel convergence and self-sealing on the long-term hydraulic properties of the EDZ has not yet been examined at full scale.

Evolution of the EDZ in salt is very sensitive to the stress state and exhibits steep transient deformation behavior that evolves into steady-state deformation. This behavior can be understood in terms of plastic dislocation mechanisms in salt crystals. Hence, creep closure of underground openings in salt at ambient temperature can be understood at a mechanistic level. Based on studies at WIPP, the nature of the EDZ can be adequately described for engineering and analysis purposes in terms of stress invariants, which is conducive to finite element calculations. Long-term behavior including healing can be assessed by tracking the stress state within the structural calculation. For the long-term disposal of high level wastes, a better understanding of rock salt creeping and fracture sealing around the EDZ at elevated temperatures and in the presence of moisture is required.

A time-dependent pore pressure response to excavation occurs in clay rocks because these media have very low permeability and high initial water saturation. Local changes in normal stress caused by excavation produce changes in pore pressure. The locally increased pore pressure decreases the effective stress acting through the solid framework, and causes dilation in directions transverse to loading. Pore water may drain in response to increased pressure, increasing the deviatoric stress. These changes, combined with stress redistribution near excavated openings, locally reduce the rock strength and produce additional deformation. A coupled hydro-mechanical model for excavation response of indurated clay/shale media would enhance understanding of these processes.

Gas production from metal corrosion and radiolysis in a clay or salt repository is a potentially important process for increasing permeability in the EDZ. Like the behavior of salt, discrete pathways that may arise from gas overpressure form from slow "creep" deformation rather than brittle fracture processes. Once a pathway forms, the pressure is relieved by gas flow, and resealing occurs, until the pressure rises again (depending on gas supply). A fully coupled thermal-hydrologic-mechanical and chemical model may help evaluate the effect of gas generation on disposal room closure.

Modeling of the excavation process, and the formation and evolution of the EDZ, is challenging. This is intrinsically a three-dimensional problem involving tunnel orientation, direction of bedding planes, and the anisotropic stress field present at the site. An elastic damage framework would help reproduce the changes in pore-water pressure. Modeling of EDZ extent depends on the constitutive law used with its choice of the elastic limit and fracturing criteria. A strain softening model may help reproduce the progressive change in material strength during excavation, in order to properly reproduce strain localization and shear band occurrences. It is important to ensure that modeling results are not mesh dependent and indeed represent the physics of the processes involved. Outstanding research issues include scale effects in adopting laboratory-measured rock properties to the study of site behavior, methods to limit damage to samples, and changes in sample hydraulic conditions from in situ to laboratory environments. 
In situ testing could prove quite valuable for proof-of-principle testing. A field test provides an opportunity to observe anticipated phenomenology, validate modeling capabilities, and fine tune design options. Focused full-scale field testing could be undertaken after the knowledge gaps that can be addressed in the laboratory are evaluated and preliminary modeling studies are complete. In situ testing confirms the predictive ability of repository models and provides a range of expected parameters and rock mass response. Full-scale heater tests can determine extent and properties of the disturbed zone under heated conditions, determine fracture healing characteristics under heated conditions, determine permeability and porosity under heated repository conditions, determine the thermomechanical response of compacted backfill under repository conditions, determine brine influx rates under heated conditions, determine water vapor pressure, and determine salt composition and structure as part of brine migration assessment.

\subsubsection{Hydrological Processes}

Better understanding of the flow processes in unsaturated, fractured rock would support improved evaluations of repository performance in these media. Thus, repositories sited in such conditions would likely require additional research and development to better understand these processes. Process understanding for flow in unfractured media or for saturated flow in fractured or unfractured media may be adequate to make meaningful predictions given sufficient site characterization. Of course site characterization and construction of site-specific flow models in the presence of inevitable uncertainty are challenging and resource-consuming tasks. Research and development to improve site characterization efficiency is discussed in Section 5.

With regard to modeling tools, it is important to make the distinction between continuum models and discrete feature/fracture models. Continuum models (including dual porosity and dual permeability models) are appropriate for unfractured porous media or for highly fractured media. Software tools implementing continuum-type models are generally more mature and capable of addressing multiple coupled processes of interest. Experience in Sweden and Finland suggests that Discrete Fracture Network (DFN) models offer advantages over continuum models for sparsely fractured media such as fractured crystalline basement rock, especially when fracture networks or network statistics are well characterized. DFN modeling capability would provide an alternative to continuum codes and would also be invaluable for numerically determining effective parameters for use in existing continuum codes. At present there are few DFN codes for modeling large-scale, three-dimensional fracture networks.

Regardless of whether DFN or continuum representations are used, repositories situated in the saturated zone present a significant flow modeling challenge, as repository tunnels and access shafts will clearly have a large influence on far-field groundwater flow patterns and need to be represented. Flow models with sufficient detail to represent all tunnels, emplacement boreholes, and access shafts have been demonstrated. However, multiple models, each representing one repository panel in detail with coarse representations of the other repository panels, or other laborious modeling strategies are likely to be required to accomplish comprehensive flow modeling using single-core desktop computers. Groundwater flow codes that take advantage of multicore architectures and/or parallel computing resources are advantageous for studies of saturated repositories.

Flow localization, caused either by large-scale flow bypass through discrete conductive features or by small scale heterogeneity, is a potentially important site characteristic affecting natural system performance. As already discussed, large-scale flow bypass can occur through intensely fractured zones, along faults, or within repository tunnels and adjacent excavation damage zones. Small-scale flow localization, whether by pervasive fracturing or geologic heterogeneity in granular media, reduces net travel time of radionuclides (through a reduction in transport porosity). The increased rate of downstream transport is partially mitigated by increased retention of radionuclides due to diffusion into relatively 
immobile water zones. The degree of flow localization and associated diffusion into immobile water are difficult to characterize and typically require field-scale tracer tests.

\subsubsection{Chemical Processes}

An understanding of geochemical conditions in the repository far-field is critical to understanding repository performance. Those conditions in the repository far field govern the mobility and solubility of radionuclides in the far-field. In addition, the chemistry of water flowing from the far field into the nearfield environment is an important control on the near-field chemical environment, which affects, in turn, the degradation of engineered system components. The geochemical conditions relevant to the performance of a geological repository for radioactive waste disposal is determined by the compositions of the host rock and groundwater, which influence radionuclide solubility, radionuclide mobility, and the capacity to buffer chemically altered water originating in the near field (carrier plumes). Host rock and groundwater compositions also determine the chemical compatibility of waste forms, containers, engineered barrier, and backfill material.

Groundwater geochemical conditions in the far-field environment are governed by the origin and mixing of source waters and by rock-water interactions in the flow system. Groundwater $\mathrm{pH}$ and major ion concentrations are usually dictated by water-rock interactions, with the rule of thumb being that waters that have spent longer residence times in a system have greater total dissolved solids loading (salinity). This rule of thumb can be affected by evaporative processes (above the water table) and by temperature gradients, particularly in hydrothermally active areas. Some rocks, such as sedimentary carbonates, are very effective at buffering $\mathrm{pH}$ and major ion concentrations because of their relatively high solubility, while other rocks have weak buffering capacity. In many locations, particularly near oceans, deeper waters tend to have higher salinity than shallow waters. Waters that have moved rapidly from the surface to the deep subsurface also tend to be more oxygenated than waters that have spent long residence times below the water table. However, oxygen can be depleted even in relatively shallow waters in areas that are densely vegetated at the surface because the presence and breakdown of organic matter in the shallow subsurface results in oxygen consumption (oxygen concentration is negatively correlated with organic carbon content in groundwaters). Oxygen depletion can also occur as water moves through rocks containing reduced metals and metal oxides.

Generally speaking, radionuclide transport tends to be enhanced in oxidizing geochemical environments relative to reducing environments because most radionuclides that can exist in multiple oxidation states are more soluble and less strongly sorbing in their higher oxidation states. Carbonate is usually considered the most important inorganic complexant in groundwater systems, as it can enhance the transport of several radionuclides that form neutral or negatively-charged carbonate complexes in solution (e.g., U, Np, Pu, Am). Higher salinity tends to suppress the sorption of cation exchanging radionuclides (e.g., Cs, Sr) because the higher cation concentrations in the water result in increased competition for cation exchange sites on minerals. Near-neutral $\mathrm{pH}$ conditions usually result in lower radionuclide solubilities and stronger sorption than either acidic or alkaline $\mathrm{pH}$ conditions, although the effects of $\mathrm{pH}$ are radionuclide specific and are often linked to the influence of $\mathrm{pH}$ on the abundance of complexing anions (e.g., carbonate) or on the surface properties of sorbing minerals in the system.

Associated with water flow localization, the spatial heterogeneity in chemical condition, specifically the redox condition, usually exists in the repository far field, which will directly affect radionuclide mobility in the far-field. Field characterization of this heterogeneity is technically challenging. In addition, chemical heterogeneity can also arise in the vicinity of a waste disposal room, where the contaminant plume leached from the disposal room, e.g., alkaline plume from cementitious materials, will interact with the ambient rock. A fully coupled reactive transport code will help capture this heterogeneity. 


\subsubsection{Transport of Dissolved Radionuclides}

The conventional approach for representing sorption in radionuclide transport modeling is through the use of an equilibrium partitioning coefficient $\mathrm{Kd}$, which quantifies the partitioning between sorbed and dissolved states. Partitioning coefficients for far-field transport modeling are typically developed for specific combinations of radionuclide, geomedium, and groundwater chemistry based on laboratory experiments and expert judgment. The Kd approach does not, however, explicitly account for changes in groundwater chemistry or mineralogy that may occur along the transport pathway. If such changes are considered possible or likely, Kd values must be spatially varied or assigned appropriate uncertainties. Temporal changes in groundwater chemistry may also occur due to changes in groundwater flow in future climate states. Degradation of engineered barriers and subsequent downstream movement of the chemically altered water (carrier plume) may also induce chemical changes affecting sorption. The Kd parameters for different radionuclides must be statistically correlated to account for a shared dependence on groundwater chemistry and mineralogy.

Surface complexation modeling, which represents surface species equilibria using mass action equations corrected for changes in electrostatic energy (e.g. electrical double layer theory), provides an alternative to the simple Kd approach. Surface complexation modeling can explicitly account for spatial and temporal changes in groundwater chemistry, including the effect of a carrier plume, albeit with increased computational burden. This modeling approach and the supporting thermodynamic data have reached a level of maturity that makes incorporation into transport models feasible, at least for simple systems.

There are additional approaches for incorporating the effect of sorption into transport models that are of intermediate complexity between a simple $\mathrm{Kd}$ model and full multispecies reactive transport simulations with surface complexation. These approaches generally are based on developing correlations between major chemical parameters and Kd using surface complexation modeling without transport. These correlations (response functions) are then be used in transport models. Such correlations can account for changes or uncertainties in groundwater chemistry within the range used to develop the response functions. Groundwater chemistry changes caused by the action of a carrier plume are, however, difficult to incorporate.

Radionuclide transport modeling remains a computationally challenging task. Except for the extreme situation of diffusion-dominated conditions, transport models are more sensitive than flow models to numerical grid effects and small-scale heterogeneity. Relatively fine grids are needed to avoid numerical dispersion when traditional finite-difference or finite-element methods are employed. Multiple radionuclides linked through decay chains need to be considered, and the simulation time steps are thus limited by the most mobile (least retarded) radioelement. In addition, transport modeling to assess geosphere performance typically requires parametric uncertainty to be addressed, which places a premium on fast execution time of modeling codes.

Because of these computational challenges, repository performance assessments often employ representative waste packages with associated representative transport pathways instead of attempting to model transport from all waste packages. All waste packages that occupy a specified region of a repository and have experienced certain conditions are typically lumped into a single representative package, for example. Package-to-package variability and pathway-to-pathway variability within the far field are not represented by such an approach. Moreover, performance studies of repositories situated in fractured crystalline rock suggest that natural system transport may be driven by a small fraction of package/pathway combinations. Because of these considerations, the use of representative waste packages introduces significant uncertainties and potential biases in repository performance studies. Streamlinebased transport codes, which neglect transverse dispersion, are efficient enough to represent transport from all failed waste packages. However, obtaining groundwater flow fields with sufficient spatial resolution to represent transport from thousands of waste packages can be challenging. Existing and 
emerging flow codes that take advantage of multicore and parallel computer architectures and clustered computer resources will make it possible to avoid the use of the representative waste package concept, thus removing one source of systemic model uncertainty.

The relative importance of representing parametric uncertainty, spatial and temporal variability, and longitudinal and transverse dispersion in transport models is each dependent on how transport performance is defined for a natural barrier. The choice of performance metric for a natural barrier depends, in turn, on how regulations regarding repository performance are framed. Regulations addressing peak of mean dose or mean geosphere discharge create different sensitivities from those that address cumulative releases, for example. Although some of the relationships are understood, a thorough systematic exploration apparently does not exist. A systematic understanding of the relationship between regulated quantity and the required level of detail in geosphere transport representations would make it possible to design more efficient modeling strategies that are adaptive to an evolving regulatory environment.

Performance assessment models of proposed and existing geologic repositories are commonly limited by the lack of definitive experimental data describing the sorption of radionuclides onto the important mineral surfaces in the natural system. For a given sorption substrate, the formation of surface complexes for actinide elements and other radionuclides of interest is highly dependent on the oxidation state of the radionuclide ions in solution and the presence of complexing agents that compete with sorption sites to bind with radionuclide ions. Thus, sorption is strongly linked to solution chemistry. The most important chemical parameters are solution $\mathrm{pH}$, reducing-oxidizing (redox) conditions, and presence of complexing agents such as carbonate ions. In addition, competition among various radionuclide ions and solution complexes for sorption sites can reduce sorption for specific radionuclide species. Sorption data obtained from laboratory-scale batch and column experiments, and especially field determinations, can be difficult to interpret due to the highly complex nature of flow in mixed-phase porous media and the interactions of fluids with complex mineral surfaces. Sorption data from the scientific literature are generally restricted to specific ranges of temperature, solution composition, $\mathrm{pH}$, and ionic strength, and therefore have limited applicability to conditions expected along transport pathways from a repository.

The last decade has seen the use of computational chemistry methods to improve the understanding of clay minerals and associated phenomena. In particular, molecular dynamics simulations have begun to provide critical adsorption data associated with the binding of various cations onto the surfaces of important clay minerals. Molecular modeling efforts have demonstrated that structures, swelling, adsorption, and related processes of clay minerals can probably be predicted. However, applying such methods to actual systems, even as simple as radionuclide sorption on edge sites of clay minerals, is yet to be demonstrated.

Although simple rock-water systems allow straightforward experimental interpretations, they also place the burden of accounting for the combined effects of reactions and physical transport, and the related issues of upscaling and system heterogeneity. This additional work is dependent almost entirely on modeling efforts. As a result, experience with upscaling results from simple rock-water experiments to the field scale has been less than satisfactory. Differences between field-scale retention and results of simple rock-water systems are likely caused, at least in part, by limited rates of mass transfer between mobile water and the immobile zones that contain sorption sites. However, the mass transfer process depends on heterogeneity across a broad range of scales and is difficult to quantify without direct experimental results at the appropriate scale. Block scale, $1 \mathrm{~m}$ scale or larger experiments could lead to a better understanding and possibly help quantify retention at the scales relevant for making geosphere transport predictions. Both fractured media and heterogeneous porous media are of interest because multiple geologic media are likely to be encountered at any one site. 
As an alternative to continuum codes, discrete fracture network flow model development coupled with advanced methods of characterizing sparse fracture networks would greatly help in the assessment of mined repositories or borehole disposal systems in crystalline basement rock. In addition, it may be useful to move beyond the use of a representative waste package modeling approach to full representation of repository geometry, especially for repositories sited in the saturated zone. Some refinement and adaptation of existing transport simulation approaches may be needed in support of that improved representation. Studies to better define the degree of detail required in transport models would also be useful to help design efficient and adaptive licensing strategies in an evolving regulatory environment.

Low-porosity geologic media such as clay formations include nanometer scale pores. For example, in a compacted bentonite, the pores are so small that the electrical double layers balancing the charge of the bentonite (typically negative at circumneutral $\mathrm{pH}$ ) overlap, thus potentially excluding anions altogether, or creating a deficiency of them within the diffuse electrical double layer balancing the surface mineral charge. It is common to observe the effects of anion exclusion, which in a diffusive regime is reflected by a late arrival (or release) of the negatively charged ions relative to neutral species. It has been shown that radionuclides may behave differently in a nanopore confinement than in large pores. The diffusion and sorption of radionuclides in nano-scale pores are particularly interesting.

\subsubsection{Colloid-Facilitated Transport}

Experience with repository performance assessments in this country and abroad suggests that radiological risk is usually driven by very mobile radionuclides such as I-129 and, counter intuitively, by strongly sorbing radionuclides such as isotopes of plutonium. Strongly sorbing radionuclides contribute in performance assessments because radionuclides that strongly associate with stationary mineral surfaces also tend to associate with surfaces on mobile colloids. However, colloid facilitated transport (CFT) may have been overestimated in previous performance assessments because many aspects of CFT are not well constrained, and thus they are often modeled using pessimistic bounding assumptions necessary. Important uncertain processes and parameters associated with CFT include desorption processes and rates, colloid immobilization processes and associated parameters, the degree to which colloids behave as heterogeneous populations in the subsurface, the role of chemical and flow transients in mobilizing and immobilizing colloids, and colloid generation processes.

The rate of desorption of radionuclides from colloids is a particularly problematic parameter. Although irreversible sorption can significantly enhance transport relative to the colloid-free case, even slow desorption can mitigate this transport enhancement. As a useful rule of thumb, CFT will be significantly reduced when desorption time scales are comparable to or less than colloid transport time scales over the distance of interest. However, given that transport time scales can be extremely long, experimental measurements of relevant desorption rates may be very difficult or impractical, especially considering the competitive processes that will occur in real systems that will likely have much more immobile surface area available for sorption than colloid surface area (a situation that is not easily replicated in longduration experiments). Moreover, analyses of radionuclide sorption/desorption experiments onto colloids have revealed more than one governing rate, with initial rates tending to be faster and thus nonconservative relative to rates observed at later experiment times.

To complicate matters further, transport depends non- monotonically on the desorption rate if colloids are filtered (permanently immobilized). This non-monotonic dependence means that if credit is taken for colloid filtration in a repository performance assessment, it will be difficult to identify a desorption rate that is bounding. Another potential complication in assessing colloid-facilitated transport is that the relatively low colloid concentrations may make it possible to saturate sorption sites with radionuclides, especially if radionuclides have a higher affinity for colloids than other system surfaces and if multiple radionuclides are competing for the same sites. Nonlinear sorption models would then be necessary. Invoking a limited number of sorption sites is one strategy for bounding colloid-facilitated transport and 
may yield a useful pessimistic bound in some circumstances. Saturation of colloid sorption sites is more likely to be an issue in the near field where radionuclide concentrations are highest.

Yet another potential complication in assessing colloid-facilitated transport is that colloid mobility itself is not well understood and colloids in the subsurface will likely not behave as a homogeneous population. A small fraction of natural colloids may move more freely (without retardation or filtration) in the subsurface, for example. If such a subpopulation of highly mobile colloids exists, then it would be important to determine whether this population also has an inherently greater affinity for radionuclides (slower desorption rates) than the bulk colloid population, thus exacerbating CFT.

Additional key uncertainties and information gaps for CFT include (1) poorly constrained generation rates and transport characteristics of colloids that are produced in the near field from engineered barrier degradation and have essentially irreversibly sorbed radionuclides (possibly embedded in the colloid matrix), and (2) the unknown effects of geochemical and hydrological transients on colloid mobilization and transport over the long time scales of repository performance assessments.

To summarize, CFT may be a significant transport mechanism for sparingly soluble and strongly sorbing radionuclides such as plutonium, which would be relatively immobile otherwise; kinetic limitations on radionuclide desorption are necessary to significantly enhance transport; desorption rates are critically important but are poorly constrained and difficult to measure; a key mitigating process, colloid filtration, is also poorly constrained and difficult to verify. Laboratory experiments will provide data to help understand fundamental colloid transport processes and radionuclide sorption/desorption onto colloids, allowing improved understanding and more realistic transport modeling. In addition, field-scale experiments will contribute to understanding scale-up of these processes to the field scale.

\subsubsection{Mechanical Processes}

The mechanical processes in a tight repository environment such as in a clay or salt repository are closely coupled to thermal, hydrologic, and chemical processes. To fully account for these couplings and their impact on repository performance requires knowledge of constitutive relationships for the host rock, especially relationships between hydraulic and mechanical properties. These relationships control the degree of coupling among the relevant processes. Although considerable efforts have been made in developing constitutive relationships, the following important issues (associated with clay rock) have not been fully addressed in previous studies:

- Water-content dependent swelling. Multiphase flow conditions develop in the excavation damaged zone (EDZ). Clay rock swells (or shrinks) with increasing (or decreasing) water content, resulting in significant rock property changes (including self-sealing of fractures). Previous studies on constitutive relationships have been focused on single-phase flow conditions and therefore their results are not applicable to swelling conditions.

- Fracture properties. Connected fractures exist within the EDZ and may serve as paths for fast flow and radionuclide transport in a clay repository. However, there are only limited studies on constitutive relationships for fractures in clay rock in the literature.

- Correlation between hydraulic and mechanical properties. Assessment of the impact of rock mechanical deformation on flow and transport needs knowledge regarding how the deformation is related to hydraulic property changes. At this stage, acceptable relationships for describing such a correlation are still lacking for fractured clay rock associated with swelling and shrinkage.

In addition, a better understanding of fractured rock issue in hard rock, or stress and fracture issues in deep crystalline rocks, especially as it pertains to borehole stability for very deep hole disposal may also be needed. 


\subsection{Research and Development Information and Knowledge Opportunities Gaps Specific to Individual Disposal Environments}

This section presents identified research and development topics that pertain to specific generic geologic environments under consideration by the UFDC.

\subsubsection{Clay/Shale}

Disposal of high-level radioactive waste in suitable shale formations is attractive because the material is essentially impermeable and self-sealing, conditions are chemically reducing, and sorption tends to prevent radionuclide transport. Vertically and laterally extensive shale and clay formations exist in multiple locations in the contiguous 48 states. Disposal of HLW/UNF in a clay/shale formation has the potential to provide effective long-term isolation of radionuclides from the biosphere because of the following hydrologic, chemical, and mechanical characteristics:

- Slow fluid movement - Fluid movement in clay or shale is slow because of very low hydraulic conductivity $\left(\sim 10^{-12} \mathrm{~m} / \mathrm{sec}\right.$ or less).

- Self-sealing - Fractures formed by excavation and heating may close and seal during repository operation and during the first few hundred years after closure. Low permeability and self-sealing of fractures around openings are primary favorable features of clay/shale media.

- Chemical conditions limit radionuclide release and transport - Reducing conditions due to the presence of organic matter will prevail at depth, which will maintain waste forms and most radionuclides at low solubilities. Sorption of radionuclides onto clays will also retard transport.

Technical studies of shale for repository purposes were engaged in the U.S. for a number of years, ending in the 1980s after passage of the Nuclear Waste Policy Amendments Act. These historical studies provide useful support for the current program. The actual experimental work was limited, however, and has been surpassed by new experimental and modeling approaches that have been developed by the scientific community in the intervening 30 years. These new methods can provide far greater precision in site characterization, repository design, and performance assessment. The new tools could be deployed in conjunction with an underground test facility, and with strengthened technical exchanges with other nations already committed to developing repositories in clay/shale media.

An underground research laboratory can help calibrate and validate models used in design, operation, and performance, and to build confidence by testing alternative models. Cooperation with clay/shale programs in Europe will provide more complete overall technical analysis of the clay/shale disposal option. This is discussed further in Section 5. One of the benefits gained from repository science development over the past 30 years is improved understanding of FEPs that are important to performance. Future performance assessment modeling should consider all relevant release scenarios and transport pathways based on FEP analyses.

Further experimental investigations will build a database that would support the identification (or certification) of volunteer sites. A technical database would support evaluation of the acceptability of proposed repository geologic media and sites. Research needs for advancing a clay/shale repository program include measurement of material properties for multi-physics representation of repository performance. International experience has shown that full-scale demonstration of disposal ("proof-ofprinciple") helps build confidence in the disposal concept of operations, and predictions of long-term performance. Validation of multi-physics predictions would be enhanced by full-scale field testing in a representative clay/shale lithology. Thermal-hydrologic-mechanical testing in laboratory and field settings 
is appropriate for mathematically describing thermally coupled clay/shale behaviors. As confidence in multi-physics models increases, they could be used to evaluate design alternatives, and to predict the outcomes from pilot-scale field tests.

The THMC responses of clay/shale media are more complex than for other disposal media. Basic research and development to support clay/shale repository science may include:

- Constitutive relationships for plastic and indurated clays based on laboratory and analytic studies. This should address issues of elastic limits and fracturing criteria, strain softening for describing progressive change in material strength, and strain localization and shear band occurrence. These constitutive relationships may help evaluate the impact of hydromechanical, chemical, and thermal processes.

- Long-term (slow) clay property changes, such as creep in plastic clays and subcritical crack growth in indurated clays. A knowledge gap exists in the evaluation of potential effects of moisture changes and temperature gradients and chemical environments on clay property changes. Appropriate handling of anisotropy and bedding planes (or in general, planes of weakness) may need to be considered.

- Interface problems, including interfaces between canister, buffer, tunnel lining and steel support as well as the in situ rock. The system behavior at the interfaces under various thermal, mechanical, and hydraulic conditions needs to be studied by laboratory experiments and numerical methods, so that they can be defined and formulated on a proper basis. The possible nonequilibrium condition at the rock wall in contact with the tunnel atmosphere, directly or through tunnel lining, might need to be taken into consideration.

- Thermo-hydro-mechanical processes in clays. These include damage mechanisms, phase changes, and interaction of multiple materials (such as those in the engineered barrier system).

- Modeling of excavation procedure and emplacement of waste and buffer. Modeling the creation and evolution of an EDZ is still an open research topic. As pointed out above, so far no single set of consistent modeling approaches has been able to reproduce all the URL observations. The thermal and geochemical effects on (long-term) EDZ evolution may need to be considered. Potential occurrence of a geochemical damage zone cannot be ruled out, and its long-term effects may need to be evaluated.

- Impact of rock-property heterogeneity as well as in situ stress fields. The permeability of indurated clays can vary over two orders of magnitude, while mechanical properties can vary by a factor of five or more. Spatial variability may have some characteristic length or may have a fractal character. Understanding clay variability could be key to predicting strain localization and fracturing processes. The stress field may also be spatially varying, depending on local structures and temporal changes in clay properties.

\subsubsection{Salt}

Use of salt formations for nuclear waste disposal has been a widely embraced concept for more than 50 years. Disposal of nuclear waste in salt remains a viable concept in the United States, as has been successfully demonstrated by more than ten years of successful operations at the Waste Isolation Pilot Plant (WIPP) near Carlsbad, New Mexico. Salt formations have naturally low permeability and selfsealing characteristics favorable to waste isolation.

Salt formation brines tend to have high concentrations of sodium, calcium, and chloride. Lesser amounts of sulfate and carbonate are likely to be present. Some brines also have high magnesium concentrations. 
The in situ pH of WIPP brines is slightly acidic (about 6.0 to 6.5). Mineral components of the salt formation buffer the $\mathrm{pH}$ to their in situ values. The $\mathrm{pH}$ of any brines after interaction with steel waste packages at low temperatures would probably be similar to that characteristic of the brucite "half buffer" ( $\mathrm{pH}$ of about 9). The $\mathrm{pH}$ of brines in contact with steel waste packages at high temperatures needs to be determined. Heating the brine could by itself change the $\mathrm{pH}$. Any buffer materials would also have an impact on the $\mathrm{pH}$. However, buffer materials should only be considered after the near-field chemical environment is characterized, based on the materials expected to be present.

There are continued benefits from research into the potential performance of a salt repository for UNF and HLW. The information that is needed to fully develop the technical basis for modeling the behavior of a salt repository can be grouped into the following areas:

- $\quad$ Response of the EDZ to combined thermal and mechanical forces

- Consolidation of backfill materials

- Availability and movement of brine and water vapor

- Gas generation and room closure

- Near-field chemsitry and radionuclide solubility controls

- Potential radionuclide transport mechanisms

The information gaps can be bridged through laboratory testing, field testing, modeling and simulations, and international collaborations.

Elevated salt temperatures will cause accelerated salt-creep deformation, which leads to a more rapid encapsulation of the waste. Laboratory studies on the salt from the field-test site are needed to examine intact and crushed salt at the high temperatures expected for salt disposal.

Most of the aspects of the geochemical model are best addressed in a laboratory because the expected repository conditions are ultimately anoxic. Geochemistry testing would include quantification of the corrosion rates of candidate waste-package and/or waste form materials in any brines that could potentially migrate to the waste package or that could otherwise enter the repository. General chemical and hydrologic conditions of natural system will set a boundary condition for waste form and waste package degradation in a salt repository. For example, the presence of hydrogen sulfides in incoming repository brines may cause copper-based waste package materials to corrode.

A comprehensive experimental data base and theoretical knowledge base for the mechanical deformation of rock salt exists, and several advanced constitutive models have also been developed and applied. However, the strong temperature dependence of the mechanical deformation of rock salt needs to be reevaluated if the salt disposal option is selected. For the calculation and assessment of the tightness of the geological barrier rock salt around a repository, further effort is also to be made in the investigation and modeling of salt damage healing and the corresponding reduction of permeability. Coupled thermomechanical benchmark 3-D simulations could be performed in order to calculate the evolution of stresses, strains, dilatant volumetric strains, and damage around a potential repository for heat-generating radioactive wastes in rock salt.

\subsubsection{Crystalline Rock}

Crystalline basement rocks are generally considered a favorable medium that could provide the required safety-related characteristics for permanent disposal of nuclear wastes. Data compiled from outcrops, cuttings and drill cores, and geophysical explorations, suggest that about $90 \%$ of the conterminous United 
States is underlain by crystalline basement rocks with large areas covered by less than $1 \mathrm{~km}$ of sedimentary and volcanic rocks and about $10 \%$ exposed at the surface. However, field and laboratory studies of crystalline basement rocks indicate that these types of rocks have long and complex history. Because of age, compositional, and structural variations, simple reconnaissance petrologic and geochemical investigations will not suffice to clearly understand the evolution of granitic rocks. Multidisciplinary and integrated field and laboratory studies will be required to identify the most favorable geological settings, containing the most appropriate crystalline basement rocks on the surface or at shallow depths.

The preferred disposal sites in crystalline basement rocks are likely to be in homogeneous rocks, which tend to be in the center of intrusive bodies or plutons. Accurately determining the shape, size, and thickness of the crystalline basement rocks are important factors during the selection process of a crystalline rock disposal site. Geophysical surveys such as seismic, gravity, aeromagnetics, and other remote sensing tools are important for characterizing the rock at the early stages, for site identifiecation and during the site characterization. At the local scale, fabric and textural features provide information about the flowage and crystallization history of the intrusive body and its interaction with the intruded host rock. At the sample level, detailed petrological, geochemical, and geochronological investigations are essential to characterize the chemical and mineralogical compositions, ages of primary and secondary minerals, alteration history related to water-rock interactions, the state of uplift and erosion, sorption properties, etc.

Discontinuities (faults, joints, fractures) are primary controls on groundwater flow in crystalline rocks. The spatial density, size distribution, orientation patterns, and transmissivity of these transmissive features are thus key site attributes. Granite formations tend to be sparsely-to-moderately fractured in regions between widely spaced zones of intense fracturing. Geophysical methods have proven to be effective at locating fracture zones in granite, which tend to be effective pathways to the biosphere. Individual fractures are, in general, not directly observable. Statistical characterization of fracture patterns through an intensive site characterization campaign, though difficult, has been demonstrated to be feasible.

\subsubsection{Deep borehole}

In this disposal option, waste packages would be emplaced in boreholes in the depth of $3-5 \mathrm{~km}$. Compared to other disposal options, such as mined geologic repositories, the disposal of nuclear waste in deep boreholes is much less studied. The future work may include:

- Detailed characterization of geologic media and flow path in the depth of interest may call for the development of new field characterization techniques.

- Modeling of the coupled thermal-hydrologic-chemical-mechanical behavior of the borehole and disturbed region during the thermal pulse, and in the presence of density-stratified waters, should be modeled with sufficient accuracy.

- Additional consideration should be focused on the design and long-term performance of deep seals.

- Modeling of both the detailed thermal-hydrologic-chemical-mechanical behavior and the fullsystem performance of multi-borehole arrays should be undertaken, consistent with an assumption that a regional borehole disposal facility could entail an array of 10-100 individual boreholes. Such investigations could elaborate on the potential for cross-hole effects, help determine minimum inter-holes distances, etc. 
- Individual preliminary performance assessment for specific regions, to establish a better sense of the potential performance variability that might be expected in multiple implementations of borehole disposal fields. Specific regions could be identified based on the availability of preexisting geohydrologic data for depths of $\sim 3$ - 5 kilometers.

In addition to the technical issues related to the post-closure performance of the deep borehole disposal system described above, several other topics that are beyond the scope of this report should be examined in further detail:

- A more comprehensive and detailed cost analysis would provide a firmer basis for quantitative comparisons with other disposal system options;

- A detailed description of the changes to legal and regulatory requirements for implementation of deep borehole disposal would provide policymakers with a roadmap for necessary actions (specifically, consideration might be given to developing a risk-based standard);

- Detailed analyses of engineering systems and operational practices for waste emplacement a to determine the viability of the deep borehole disposal concept. Also, the advantages of applying deep borehole disposal in countries possessing smaller and/or non-fuel waste inventories should be explored further.

A full-scale pilot project, perhaps with surrogate waste, to fully explore the viability of a borehole disposal concept could be highly valuable. The scientific and engineering advances gained from a single pilot project, and the applicability to subsequent borehole disposal implementations, are fairly general and would be applicable to the deep borehole concept wherever it would be location. This is a contrast to sitespecific mined repositories and their unique site characterization demands with relatively little transferable knowledge to subsequent repositories. Given the potential for standardizing the borehole design, and thus the ready extension to multiple borehole facilities, a single pilot project could provide significant gains on the scientific and engineering issues needing to be resolved, enable the development of international standards, and accelerate the evaluation of the viability of deep borehole disposal of spent nuclear fuel and high-level radioactive waste. A candidate plan and timeline for such a pilot project should be developed to provide a basis for future consideration of implementation of this option.

\subsection{Bibliography for Section 3}

Brady P. V., Arnold B. W., Freeze G. A., Swift P. N., Bauer S. J., Kanny J. L., Rechard R. P., and Stein J. S. (2009) Deep Borehole Disposal of High-Level Radioactive Waste, SAND2009-4401, Sandia National Laboratories, Albuquerque, NM.

Hansen F. D., Hardin E. L., Rechard R. P., Freeze G. A., Sassani D. C., Brady P. V., Stone C. M., Martinez M. J., Holland J. F., Dewers T., Gaither K. N., Sobolik S. R. and Cygan R. T. (2010) Hale Disposal of U.S. High-Level Radioactive Waste, SAND2010-2843, Sandia National Laboratories, Albuquerque, NM.

Hansen F. D. and Leigh C. D. (2010) Salt Disposal of Theramlly Hot Nuclear Waste, Sandia National Laboratories, Albuquerque, NM. (draft).

Wang Y. (ed.) (2010) Natural System Evaluation and Tool Development - FY10 Progress Report, Fuel Cycle Research \& Development, August 23, 2010.

Wang Y., Bryan C., Gao H., Pohl P., Brinker C. J., Yu K., Xu H., Yang Y., Braterman P. S., and Xu Z. (2003) Potential Applications of Nanostructured Materials in Nuclear Waste Management, SAND2003-3313, Sandia National Laboratories, Albuquerque, NM. 


\section{Engineered System}

This section identifies research and development needs within the engineered system for the generic geologic media under consideration by the UFDC and further details are given in the Disposal Systems Evaluations and Tool Development - Engineered Barrier System (EBS) Evaluation Final Report (JovéColón et al. 2010). This section presents the R\&D for each of the key features of engineered systems: the waste form, the waste container/package, buffer/backfill, and seals.

\subsection{Waste Form}

The waste form is the most "interior" part of the engineered barrier system and is a fundamental part of a multiple barrier system for isolating radionuclides. Two campaigns within the Fuel Cycle Technology program are investigating waste form durability and behavior. The Separations / Waste Form campaign is responsible for conducting $\mathrm{R} \& \mathrm{D}$ related to waste forms that would be generated from separations/ recycling processes. A wide variety of waste forms are under investigation within that campaign. A research and development roadmap for these investigations has been developed and is being implemented. The UFDC is responsible for conducting R\&D to enable the direct disposal of used nuclear fuel as a waste form in a geologic environment, should that decision be chosen. This section discusses waste form related R\&D gaps, focusing primarily on used nuclear fuel as a waste form and the interface between UFDC and Separations / Waste Form campaign activities for advanced fuel cycle processing waste forms.

There are clear interfaces between UFDC and Separations/Waste Form campaign R\&D activities. The conditions within the engineered system, both thermal and geochemical, affect the performance of the waste form. These conditions depend on the other engineered barriers that could be used in the design of a repository. The manner that the waste forms degrade, the rate, the degradation products that form, and the resultant geochemistry, affect the radionuclide source term entering the remainder of the engineered system. Thus strong collaboration between the UFDC and Separations/Waste Form campaigns is essential. The R\&D Roadmap will identify the key interactions, interdependencies, and interfaces between the UFDC work on repository systems and the Separations/Waste Form campaign work on waste forms.

\subsubsection{High Level Waste}

There are several important attributes that affect the long-term performance of the waste as an effective means of radionuclide immobilization:

- The ability to accommodate high levels of waste loading - This is important to the minimization of waste volume that could translate into reduction in numbers of waste packages and spatial gains at the disposal site.

- Simple and safe fabrication - The practical realization or synthesis of any waste form concept should require straightforward manufacturing and/or processing conditions that are inherently safe and cost effective along with minimization of additional waste streams. Also, the integrity evaluation of waste form concepts needs to be synchronous with fabrication practices in the form of a performance testing program.

- Stability against prolonged radiation - The waste form should be tolerant to extended exposure to various forms of radiation and the damage caused by such process. 
- Versatile immobilization chemistry - The waste form material should possess a multi-faceted quality capable of confining a wide variety of radionuclides and related substances while minimizing any potential for eventual nuclear material releases.

- Durability - This is a very important attribute of the waste form in terms of longevity and resistance to various forms of material degradation for long-periods of time given the long halflives of many radionuclides.

- Natural analogues - These are the geologic manifestation of long-term exposure of what could be closely-related to waste forms in the natural environment. Scientific observations of site-specific examples of natural analogues can provide important information of long-term alteration of mineral assemblages, spatio-temporal mechanisms for radionuclides migration, and elucidation of important processes relevant to the long-term performance of the repository.

There are several types of waste forms being considered by the OFCT Separations/Waste Form Campaign:

- Metallic

- Ceramic

- Glass

Others waste forms are also being investigated. A common R\&D goal for both the Separations/Waste Form campaign and the UFDC is to identify and develop waste forms that can allow for high waste loadings without a large increase in overall waste volume and long-term compromises in chemical and mechanical integrity of the material as a result of thermal and chemical processes along with interactions in the near-field environment.

Waste form durability/longevity is a key measure of degradation resistance. Some of the issues associated with durability/longevity are: (1) corrosion and dissolution of the waste form phase through interactions with the natural environment, (2) resistance to radiation effects, (3) long-term resistance to thermo-mechanical damage, (4) long-term resistance to material degradation (e.g., devritification, phase changes). Several of these processes depend not only on the properties of the waste form itself, but also on the boundary conditions imposed by the natural system and other engineered barriers.

In particular, the local redox environment can have a significant effect on the waste form. Reduced environments within the engineered system are typically highly desirable, protecting not only the waste form, but other engineered barriers as well. Long-term maintenance of a reduced environment, particularly at EBS interfaces, can be considered as a key chemical barrier. One form of "chemical conditioning" of the local EBS is the redox environment by the addition of tailored backfill materials that could maintain such redox conditions. For example, the addition of metallic barrier materials such as steel liners that even when degraded in the form of secondary oxy-hydroxides phases, can maintain reduced conditions for extended periods of time.

\subsubsection{Used Nuclear Fuel}

Several of the fuel cycle scenarios under consideration by the FCT program could involve the direct deep geologic disposal of used nuclear fuel. The U.S. efforts to develop a geologic repository at Yucca Mountain, Nevada involved the direct disposal of UNF in an oxidizing environment. Other countries are planning for the direct disposal of UNF in reducing environments. 
Much of this research has been devoted to the study of fuel cycles that would include the direct disposal of light water reactor (LWR) fuel. Advanced reactor concepts could, if deployed, introduce other fuel types that may be directly disposed. These reactor concepts include advanced LWRs with higher discharge burn-up, advanced gas cooled reactors (potentially using Tristructural Isotropic - TRISO fuel), and thorium-fueled reactors. Additional research would be needed to understand how these fuels would behave in a geologic disposal system and to develop models that could ultimately be used in a demonstration of safety.

Knowing the radionuclide inventory for the different fuel types (and high level waste forms) is an initial condition in evaluating engineered system and overall disposal system performance. Gap and grainboundary regions are very important for heterogeneous UNF domains that can strongly influence inventories in these interfacial regions. These are also strongly dependent upon the burn-up and power history of the fuel and can therefore affect radionuclide release estimations. For example, the preferential radionuclide accumulation (fraction) and eventual releases from grain boundaries could render certain radionuclides readily available for dissolution during fuel degradation. Therefore, accurate knowledge of radionuclide inventories at gap and grain boundaries is needed to estimate radionuclide release rates and to constrain associated uncertainties. Close interface with the FCT Fuels campaign is needed.

Criticality safety analysis of UNF takes into account the burn-up credit as a result of the potential for diminished reactivity due to fuel irradiation. Criticality safety analyses extend beyond disposal into both the storage and transportation of UNF. Accounting for burn-up credit may allow for a larger waste loading capacity for a given fuel cask design relative to that adopted based on "fresh" nuclear fuel, with potentially large economic benefits. Estimation of the burn-up credit requires accurate evaluation of nuclear fuel assembly inventories with burn-up and enrichment which is mainly carried out by code calculations. Therefore, there is the necessity for code validation in calculations involving the use of benchmarks, prediction of isotopic compositions, and quantification of biases including the bias uncertainty for predicted used nuclear fuel compositions.

A capability to simulate and defensibly evaluate risks and consequences associated with criticality excursions in operations involving UNF, defense, and commercial nuclear waste is needed. These operations extend beyond geologic disposal and include storage, transport, and reprocessing operations. This capability would support informed decision making relative to design, safety, and licensing of spent fuel systems and facilities. To-date, studies along these lines have been rather approximate and performed via development and use of problem-specific, single-purpose, software that while sufficient to support demonstrate safety, could benefit from additional investigation to support model validation and improve confidence.

Critical experiments may provide additional support for validation of postclosure criticality analyses may be needed. Critical experiments that represent the isotopic compositions and degraded fuel configurations expected during the disposal timeframe, as well as compositions and configurations relevant to reprocessing operations could lead to expanded credit for fuel burn-up, and associated design and licensing benefits.

Used fuel isotopic composition measurement capabilities would support both activities above. These include destructive radiochemical assay (isotopic composition) measurements for commercial used nuclear fuel to support validation of burn-up estimates and credit critically analyses for spent fuel storage, transport, disposal, and reprocessing operations to obtain sufficient validation data that is representative of the waste stream. Benefits are related to the approval and expanded credit for fuel burn-up (and associated cost savings), expedited licensing, and reduced analysis conservatism. Such data would also benefit the broader DOE-NE programs in that the capabilities would benefit future and advanced fuel type design and modeling. 
The performance of zircaloy cladding as a barrier has been investigated extensively. The potential for cladding credit based on the effects of cladding corrosion and mechanical failure modes has been evaluated and it was concluded that cladding, whether intact or damaged, has the capacity of limiting radionuclide releases given the zircaloy high resistance to corrosion and mechanical behavior when damaged. Mass transport of radionuclides through cracks and pin-holes is interpreted as being hindered by the heterogeneous spatial distribution of failed zones between the outer- and inner-rim domains of the cladding phase.

However, there are knowledge gaps on additional processes relevant to cladding degradation such as stress corrosion cracking (SCC), hydride embrittlement (HE), delayed hydrogen cracking (DHC) coupled with hydride reorientation, and mechanical failure due to fuel-clad interactions. In particular, there are important knowledge gaps on the nature of these processes at elevated temperatures or for thermal regimes typical of backfilled repositories.

However, more research is needed in the mechanistic understanding of cladding breakdown where all the above-mentioned degradation modes may act simultaneously and could very well be affected by temperature; an important parameter to be considered in backfilled repositories. Therefore, cladding credit should be seriously considered in the form of an additional barrier as part of the waste form.

Material measurements and computational modeling related to cladding and fuel performance in storage, transport and disposal operations involving commercial spent nuclear fuel could support informed decision making relative to design, safety, and licensing of spent fuel systems and facilities. Such efforts could help address unresolved questions related to cladding performance during prolonged storage periods and transportation following prolonged storage, particularly for high burn-up fuel.

\subsection{Waste Container}

The waste container, or waste package, is one of the primary engineered barriers in the design of geologic disposal systems. The relative contribution of the waste container to overall waste isolation differs depending on the design of the facility and the geologic environment. Given the importance of the waste container, the degradation of potential waste container materials has been investigated extensively both in the U.S. and other nations. For example, degradation mode surveys have been documented (e.g. Farmer, 1988a,b, Gdowski, 1988a,b and Bullen, 1988) for waste package candidate materials to be used at Yucca Mountain. These included three austenitic alloys (304L, 316L and Alloy 825) and three copper alloys (CDA 102, CDA 613 and CDA 715) used in the nuclear industry and marine environments, respectively. The work contains information on phase stability, environmental effects of a repository, general corrosion, localized corrosion, stress corrosion cracking, hydride cracking, microbially-influenced corrosion and internal corrosion of candidate HLW package materials. The COBECOMA report (Kursten et al. 2004) summarizes various corrosion activities by European countries and provides corrosion rates for various metallic phases.

Addressing the uncertainty associated with extrapolating relatively "short-term" corrosion rate measurement data to the longer time periods and to the spatially variable conditions needed for addressing repository performance is a key $\mathrm{R} \& \mathrm{D}$ need. The development and application of predictive models for re-passivation potential under various environmental conditions and solution chemistries is needed. A compilation of data regarding passive film breakdown would support this effort.

Better understanding of localized corrosion effects, in particular stress corrosion cracking, pitting, and crevice corrosion would lead to improved modeling and understanding of waste package performance. Experiments to investigate localized corrosion resistance at various environmental conditions would help identify the most the most resistant metals in given environments. These experiments would also be used to develop improved, mechanistic models of localized corrosion processes. 
Stress corrosion cracking (SCC) does not appear to play a big role on copper canister corrosion, even at elevated temperatures. In other repository programs such as Canada and Japan, stress corrosion cracking is not considered on the basis of chemical threshold concentrations and low amounts of SCC agents for this process to occur. Further needs related to SCC include:

- Comprehensive compilations of studies on SCC for many type metallic barriers

- Acquisition of better understanding of chemical agents and temperature conditions for promoting SCC.

- Development of a consensus summary from various countries on the role of SCC on metallic barriers considered for waste disposal.

Long-term effects such as hydrogen embrittlement, de-alloying, creep, segregation, radiation damage, oxide wedging, and the effect of radiolysis on the potential aqueous phase in contact with metallic barriers are also important and would benefit from further studies. Some issues related to radiolysis deserve attention are:

- Radiolytic effects on brine solution with various types cations and anions,

- Characterization of temperature effects,

- Accurate characterization of the effect of $\mathrm{H}_{2} \mathrm{O}_{2}$ caused by major changes in near-field chemistry as a consequence of radiolysis.

\subsection{Buffer/Backfill}

Repository design concepts in saturated media typically involve the use of backfill and/or buffer materials. These materials can serve both as a physical and chemical isolation barrier.

Many minerals such as clay and gypsum contain water in the form of water molecule and/or hydroxyl. Clays, in particular, are present in significant amounts in many rocks surrounding potential geological repositories and are very important EBS buffer/backfill materials. When these minerals are heated above their dehydration/dehydroxylation points, due to radiation decay and any other heat sources, they decompose into water (liquid or vapor) and other minerals (typically denser phases). This process will release water to the neighboring environments. It may also reduce the volumes of the minerals, thereby causing changes in host rock strength, porosity, and permeability. These processes may affect groundwater flow, geochemistry, and thus related radionuclide transport. The extents of these effects may vary considerably, depending on the type of hydrous mineral, its dehydration/dehydroxylation temperature, its content in the host rock, the rock's location (both relative to the waste loadings and its depth), and thermal profile (as a function of time) of the repository.

Potential research areas that deserve attention include:

- Backfill/buffer stability:

- Clay dehydration. This is a step function that involves large and sudden volume changes that are related to release of water with the loss of water layers.

- The thermal behavior of smectites. This process may involve several phenomena: (1) reversible collapse/expansion of the smectite layers due to loss/gain of interlayer water at water vapor pressures < $1 \mathrm{~atm}$; (2) irreversible collapse of the smectite layers due to loss of interlayer water and migration of interlayer cations into the layers; (3) irreversible reduction of the osmotic swelling capacity of smectites in a steam atmosphere; and (4) inhomogeneous transformation of smectites into interstratified illites/smectites at 
temperatures $>300{ }^{\circ} \mathrm{C}$. Of these four types of thermal reactions, reversible collapse and collapse in a steam environment probably play more important roles in a repository environment.

- Thermodynamic description of clay dehydration. Vidal and Dubacq (2009) provided thermodynamic modeling of clay dehydration and their chemical evolution with regard to temperature, pressure, and water activity. The authors conclude that additional experiments at high pressures and temperatures are required to confirm the apparent inconsistencies between their model and the few available high-pressure experimental data.

- Sulfate stability. This is a relevant issue to salt repositories. Gypsum dehydration and phase transitions issues indicate a need for better mapping of phase stability relations in the $\mathrm{Ca}-\mathrm{SO}_{4}-\mathrm{H}_{2} \mathrm{O}$ system.

- General issues of salt backfill. These include self-healing properties, consolidation/creep behavior and compaction of crushed salt at high temperatures, bedded vs. dome salt formations, gas generation as a result of radiolysis and corrosion of metallic barrier materials. THMC issues in salt include:

$\circ$ Brine migration

- Vapor phase and moisture transport

- Buoyancy effects

- Drift stability as a result of HLW heat generation

- Radiolysis and gas generation

- Radionuclide transport and solubility in concentrated brines

○ Colloid transport

- Data needs to assess chemical and structural changes in clay materials:

$\circ \quad$ X-ray diffraction (XRD) data - variations of the basal spacings as a function of vapor pressure for various smectites as well as other clay minerals,

- Degradation of clay minerals as a function of temperature and water/clay ratio,

- Further study of rehydration hysteresis over the spectrum of clay chemical species,

- Experiments at high pressures and temperatures are required to confirm the apparent inconsistencies between the model of Vidal and Dubacq (2009) and the few available high-pressure experimental data,

$0 \quad$ Pressure $(\mathrm{P})$-temperature $(\mathrm{T})$ diagrams showing the dehydration reactions of hydrous minerals, such as Na-, K-, and Ca-smectites,

- Environmental scanning electron microscopy (SEM) data of water sensitivity of rocks containing clay minerals,

○ Thermodynamic data for a wide range of clay phases to allow for modeling of clay/solution interactions.

Geological repositories for disposal of high-level nuclear wastes generally rely on a multi-barrier system to isolate radioactive wastes from the biosphere. The multi-barrier system typically consists of a natural barrier system, including repository host rock and its surrounding subsurface environment, and an engineering barrier system (EBS). Considering the interrelationships that exist between these processes, the following list of studies relevant to THMC coupled processes has been identified:

- $\quad$ Studies of bentonite hydration to include new processes not included in conventional formulation of THM models. These processes include thermo-osmosis, microstructure evolution, existence of different states of water in the bentonite, and existence of a threshold hydraulic gradient for water flow.

- Studies of THM behavior of bentonite pellets and pellet mixtures, and irreversible swelling or compression of bentonite in large gap fillings. This is related to homogenization of the bentonite 
density in the EBS materials such as bentonite blocks, pellets, and gaps to serve as an effective isolation barrier to radionuclide leakage.

- Studies of piping and erosion of bentonite. The loss of mass into flowing water needs to be limited. Experimental data are needed to verify our understanding.

- $\quad$ Studies of radionuclide transport through bentonite interlayer porosity. Expand the existing capabilities for modeling of diffusive transport in compacted bentonite for modeling transport through montmorillonite interlayer porosity. Model validation is very important.

- Studies of swelling and self-sealing. Well established model methodologies of these important phenomena and their relations to reactive transport are lacking in the literature.

- $\quad$ Studies of gas generation and its modeling. Gas generation and flow have an important impact on mechanical, chemical, and hydraulic processes in the EBS. Gas pressure and migration may result in preferential pathways for gas flow and radionuclides that partition into the gas phase. Preferential gas flow along higher-permeability pathways through the EBS could result in fast gas-phase transport to more permeable formations external to the host rock or even the ground surface. Gas flow will also lead to aqueous phase displacement and aqueous radionuclide transport.

- $\quad$ Studies considering explicit interactions between host rock and EBS and between different EBS components. Interactions between EBS components and associated interfaces are disregarded or highly simplified (e.g., waste form interaction with corrosion products and buffer materials). Develop the capability to investigate the interplay between the different components and their interactions via mechanistic process coupling. This interplay may have an important impact on radionuclide release from the EBS.

- Studies of chemical/mineralogical changes in bentonite. Aqueous chemical and mineralogical changes, including illitization, $\mathrm{Na} / \mathrm{Ca}$ exchange, reactions with alkaline waters from cementitious materials, reactions with corrosion products, and secondary mineral precipitation affect mineral volume and mechanical characteristics. Potential for induration of the bentonite through these changes and fracturing caused by changes in mineral volumes, thermal expansion/contraction, volume changes associated with changes in pore-water composition, and volume changes caused by mineral transformations need to be evaluated.

- $\quad$ Studies of radionuclide sorption on bentonite for varying conditions, including temperature, $\mathrm{pH}$, Eh, mineral phase (e.g., illitization), and $\mathrm{Na} / \mathrm{Ca}$ exchange. Numerous observations of sorption indicate varying levels of sensitivity to temperature, pore-water and mineral compositions, depending on radionuclide species. The effects of iron corrosion products on bentonite include increased $\mathrm{pH}$ and precipitation of magnetite, which can lead to stronger sorption in the backfill. Thermodynamic databases need to be expanded so that predictions of radionuclide sorption can be made over the range of conditions that may occur.

- $\quad$ Further integration of THM \& C models for simulating THMC coupled processes. Significant chemical-mechanical couplings for bentonite mean that the traditional separation of THM and THC coupled processes in most existing software may not be adequate. Given the compatibilities of their software structure, integration of TOUGHREACT with TOUGH-FLAC as a fullycoupled THMC software code is one avenue to consider in attaining this goal.

- Analysis of recent field data from major bentonite experiments. Examples are the Canister Retrieval Tests (CRT), Thermal Bentonite Test (TBT), and the to-be-conducted Bentonite-Rock Interaction Experiment (BRIE). Some of the data may be found from the published literature or 
open company reports, while others may be available only through participation in international cooperative projects. Such participation, however, is an effective way to be positioned at the forefront of the state of science in this field.

- Colloid sorption and transport: Colloid transport can be a significant at barrier interfaces. It could also be a rather efficient transport mechanism for radionuclides in a porous or fractured media. Colloid filtration can also be an important property of the barrier and needs to be further investigated. There are significant experimental data needs and also modeling gaps with regards to colloid chemistry and transport, particularly for radionuclides such as $\mathrm{Pu}$.

- $\quad$ Added materials: Getters can be efficient sorbers of radionuclides. Moreover, addition of metallic materials to the backfill/buffer phases can also condition the local redox state of barrier to prevent radionuclide transport. The potential for chemical conditioning of the EBS and thus the near-field environment is important for the overall EBS performance and need to be further investigated.

- Hydrochemistry: The hydrochemical characteristics of deep-seated waters is important in terms of potential interactions with EBS components. Several studies have identified groundwater compositional trends along with redox conditions. However, more work is needed to further provide a better understanding of groundwater chemistry for various host-rock types, particularly in studies that involve site-specific hydrochemical characterization. Some existing studies are summarized in Jové-Colón et al. (2010).

\subsection{Seals}

Seal material, particularly cementitious phases, constitutes an important part of the EBS physical and chemical environment. Concrete in an underground nuclear-waste repository serves a direct function as a structural or sealing material in the engineered-barrier system. In addition, concrete may serve a designed or gratuitous function as a moderator of groundwater chemistry.

- Cement chemistry and thermodynamic modeling: The existing compilation of thermodynamic and solubility data developed for the Yucca Mountain repository was restricted to cement phases for which either solubility and/or thermodynamic data are well-constrained, even for the common cement phases. For the purpose of establishing the groundwork for a modeling framework for cementitious materials these data are useful even with all inherent limitations on data availability, uncertainties, and compositional variability present in cement phases. The following are tasks related to these issues that would benefit from further treatment:

- Expand and extensively refine existing thermodynamic databases. Also, this development needs to be aimed at bridging consistency in the retrieval of thermodynamic data.

- Create a catalog of test cases and benchmark problems for predicted thermodynamic properties and solubilities of cement phases. This could be in the form of predicted solubilities versus experimental data as function of temperature. Also, establish benchmark cases for cement hydration.

- Create a catalog of cement leaching data and corrosion under various chemical conditions. Leaching data can be very useful in establishing model confidence and could also serve as a benchmark test. 
- Expand thermodynamic modeling methologies to include $\mathrm{C}-\mathrm{S}-\mathrm{H}$ cement solid solutions between $\mathrm{Ca}(\mathrm{OH})_{2}$ and $\mathrm{SiO}_{2}$ to capture the large range of $\mathrm{Ca} / \mathrm{Si}$ ratios for the compositional variability exemplified by hydrated cement mixtures. Modeling solid solution of cementitious phases can be very useful in the evaluation of cement corrosion processes such as carbonation.

- Establish synergies with other research programs such as the Cementitious Barriers Partnership (CBP) which is sponsored by DOE-EM. Other potential synergies could be established with European programs on cement research having similar goals.

- Cement type options for nuclear waste repository environments. Data are needed to better understand these candidate cement materials and their degradation behavior:

- Geopolymers: These are a family of cementitious materials formed by subjecting aluminosilicate phases (e.g., kaolinite clay) to highly alkaline hydroxide (and/or silicarich) solutions in order to form certain types of binder and concrete materials

- Salt-saturated concretes: This type of cement has a composite nature made from a mixture of $\mathrm{NaCl}$, sand and gravel, fly-ash, $\mathrm{CaSO}_{4} \cdot 0.5 \mathrm{H}_{2} \mathrm{O}$, and Portland cement. This type of concrete was developed to mitigate cement degradation when exposed to saline solutions in salt repositoy environments.

○ Low-pH concretes: Low-pH concretes refer to cementitious materials with the least amount of portlandite $\left(\mathrm{Ca}(\mathrm{OH})_{2}\right)$ as a binder and instead having a high silica content (silica fume or fly-ash) to provide more resistance to potential deleterious interaction with groundwaters.

- Natural analogs: There is a need to expand the current knowledge base of ancient cement technologies that have resisted extensive weathering and other deteriorating processes for long periods of time:

- Pozzolanic cement contained volcanic ash (pozzolana) that included easily soluble silica and alumina. Others contained crushed terra cotta or brick.

- Concretes and mortars having calcium carbonate plus crushed brick material, calcium aluminosilicates and a hydrated calcium sulfoaluminate (ettringite type).

- Ancient geopolymer concretes that are similar to the synthetic ones made today having remarkable durability.

- Asphalt seals: Asphalt is well characterized for its mechanical properties as a sealant, especially in salt repositories such as the WIPP site. Several issues that deserve further investigation are:

- Biodegradation of bitumen

- Potential for asphalt to act as a redox barrier

$\circ$ Effects of organic volatility at high temperatures and potential for acid generation

○ Potential interactions with other EBS and seal materials (e.g., cements). 


\subsection{Bibliography for Section 4}

Ahn, T. M., G. A. Cragnolino, et al. (1999). "Scientific bases for cladding credit as a barrier to radionuclide release at the proposed Yucca Mountain repository." $\underline{\text { Scientific Basis for Nuclear }}$ Waste Management Xxii 556: 525-533.

Anderko, A., N. Sridhar, et al. (2004). "A general model for the repassivation potential as a function of multiple aqueous solution species." Corrosion Science 46(7): 1583-1612.

Bullen, D. B. G., G. E. (1988). Phase Stability - Vol. 1. U.S. DOE, Lawrence Livermore National Laboratory. UCID-21362.

Davidovits, J., (1989). “Geopolymers and geopolymeric materials”, Journal of Thermal Analysis, Vol. 35, p. $429-441$.

Davidovits, J., (1991). “Geopolymers - inorganic polymeric new materials”, Journal of Thermal Analysis, Vol. 37, p.1633-1656.

Davidovits, J., (1993). “Are modern cements better than ancient cements?”, Structural Survey, Vol. 2(2), p. $124-129$.

Davidovits, J., (2008). "Geopolymer - Chemistry and Applications", Geopolymer Institute, 592 pp.

Dole, L.R. and Mattus, C.H., (2007). "Low pH concrete for use in the US High-Level Waste repository: Part I Overview," $3^{\text {rd }}$ Workshop on R\&D on Low-pH cement for a Geological Repository, Paris, France, June 13 -14.

Duxson, P., Fernandez-Jimenez, A., Provis, J.L., Lukey, G.C., Palomo, A., and Van Devender, J.S.J., (2007). "Geopolymer technology: the current state of the art", J. Mater. Sci., Vol. 42, p.29172933.

Farmer, J. C., R. D. McCright, et al. (1988). Survey of Degradation Modes of candidate Materials for High-Level Radioactive-Waste Disposal Containers- Vol. 3 Overview. U.S. DOE, Lawrence Livermore National Laboratory. UCID-21362.

Farmer, J. C., R. A. Van Konynenburg, et al. (1988). Survey of Degradation Modes of candidate Materials for High-Level Radioactive-Waste Disposal Containers- Vol. 3 Localized Corrosion and Stress Corrosion Cracking of Austenitic Alloys. U.S. DOE UCID-21362.

Feron, D., D. Crusset, et al. (2008). "Corrosion issues in nuclear waste disposal." Journal of Nuclear Materials 379(1-3): 16-23.

Furuya, T., T. Fukuzuka, et al. (1983). "Gamma-Ray Irradiation Effects on Stress Corrosion Cracking of Alloys for a High Level Liquid Waste Package." R-D Kobe Sielosho Gijutsu Hokoku 33(1): 4346.

Gdowski, G. E. and D. B. Bullen (1988). Effects of Hydrogen in Austenitic and Copper-Based Alloys Vol. 6. U. DOE, Lawrence Livermore National Laboratory. UCID-21362.

Gdowski, G. E. and D. B. Bullen (1988). Oxidation and Corrosion - Vol.2. U.S. DOE, Lawrence Livermore National Laboratory. UCID-21362.

Jové Colón, C. F., Caporuscio, F. A., Levy, S. S., Xu, H., Blink, J. A., Halsey, W. G., Buscheck, T., Sutton, M., Serrano de Caro, M. A., Wolery, T. J., Liu, H-H, Birkholzer, J., Steefel, C. I., Rutqvist, J. Tsang, C-F, Sonnenthal, E., Final Report: Disposal Systems Evaluations and Tool Development - Engineered Barrier System (EBS) Evaluation, 2010. Fuel Cycle Research and Development, DOE-NE Used Fuel Disposition Campaign, Submitted September 8th, 2010, 197 pp. 
Kursten, B., E. Smailos, et al. (2004). COBECOMA - State-of-the-art document on the COrrosion BEhaviour of COntainer MAterials, European Commission; $5^{\text {th }}$ EURATOM Framework Programme 1998-2002. Final Report.

Laidler, J. J., J. E. Battles, et al. (1997). "Development of pyroprocessing technology." Progress in Nuclear Energy 31(1/2): 131-140.

Peters, M. T., R. C. Ewing, et al. (2008). GNEP Waste Form Campaign Science \& Technology and Modeling \& Simulation Program: Roadmap With Rationale \& Recommendations, U.S. DOE. GNEP-M50-3040-303; GNEP-M50-3030-101: 49 pp.

Radulescu, G. (2010). Propagation of Isotopic Bias and Uncertainty to Criticality Safety Analyses of PWR Waste Packages. U.S. DOE. Oak Ridge, TN, Oak Ridge National Laboratory; UT-Batelle, LLC: 45.

Rodriguez, C., A. Baxter, et al. (2003). "Deep-Burn: making nuclear waste transmutation practical." Nuclear Engineering and Design 222(2-3): 299-317.

Vidal, O. and B. Dubacq (2009). "Thermodynamic modelling of clay dehydration, stability and compositional evolution with temperature, pressure and $\mathrm{H}_{2} \mathrm{O}$ activity." Geochimica Et Cosmochimica Acta 73(21): 6544-6564.

Wakeley, L.D., (1987). "Optimizing workability and expansion of a salt-saturated concrete”, Cement and Concrete Research, Vol. 17, p. 723-733.

Wakeley, L.D., Poole, T.S., Ernzen, J.J., and Neeley, B.D., (1993). "Salt saturated mass concrete under chemical attack", in High Performance Concrete in Severe Environments (SP-140), P. Zia (ed), American Concrete Institute, p. 239-267.

Yim, M. S. and K. L. Murty (2000). "Materials issues in nuclear-waste management." Jom-Journal of the Minerals Metals \& Materials Society 52(9): 26-29. 


\section{Repository System}

This section summarizes research and development needs pertaining to the entire repository system. It first discusses overall disposal system-level modeling, followed by discussions on operational-relelated R\&D needs and knowledge management systems.

\subsection{Disposal System Modeling}

Disposal system modeling will be conducted at two levels within DOE-NE. The UFDC is developing generic disposal system environment (GDSE) models to support its activities over the short-intermediate timeframes. These models will provide a capability for evaluating disposal system performance so as to inform and guide UFDC R\&D activity prioritization and to evaluate disposal-related metrics for fuel cycle system analysis and system engineering activities. These models include generic performance models of long-term repository performance (i.e., performance assessment) and simplified thermal models to evaluate the thermal impacts of different fuel cycle strategies (i.e., thermal limits, repository layout, needed decay storage).

The DOE-NE Nuclear Energy Advanced Modeling and Simulation (NEAMS) program is developing advanced high-fidelity, fully-coupled, multi-physics models for disposal systems for disposal-related processes. The NEAMs effort will also involve developing abstractions of these high-fidelity models into a system-level framework, both of which may ultimately support future safety analysis and licensing efforts, representing an enhancement of the modeling capabilities used to support WIPP certification and the Yucca Mountain license application. The UFDC and NEAMS timelines and the system-level modeling activities are shown in Figure 3.

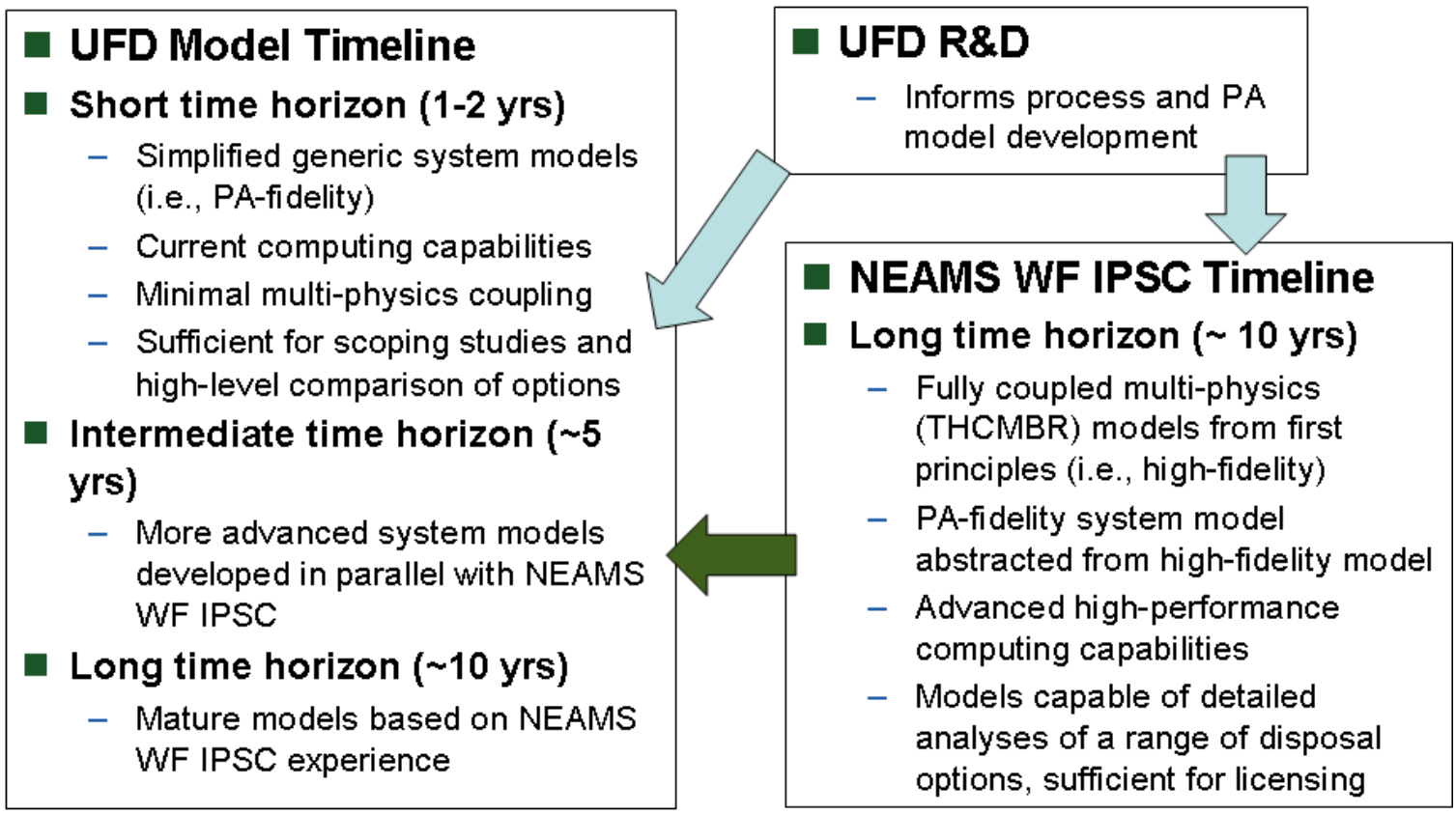

Figure 3. UFDC and NEAMS Disposal System Model Development Activities

UFDC R\&D will support the development and improvement of the GDSE models and the development of the NEAMS Integrated Performance and Safety Code (IPSC) development. For a period of time, the 
UFDC GDSE models will be improved, but ultimately the mature NEAMS IPSC models will be used. Experimental investigations and model development completed as part of the UFDC program will support both the GDSE and NEAMS IPSC model development.

\subsection{Operations-Related Research and Technology Development}

Understanding long-term disposal system performance is not the only challenge facing the U.S. waste management program. Whatever the path forward for management of spent fuel and high-level waste in the U.S., implementation of a national system will require routine and reliable handling of those materials at unprecedented amounts and rates, substantially higher than those facing other countries.

In March 1993, a DOE Office of Civilian Radioactive Waste Management task force issued A Proposed Alternative Strategy for the DOE Civilian Radioactive Waste Management Program. The report's recommendations included early development of an offsite waste packaging $R \& D$ facility to resolve issues concerning package fabrication, closure, and handling, and produce confirmatory data for the repository licensing proceeding. The report further concluded that such a facility could also serve as a center for an ongoing $\mathrm{R} \& \mathrm{D}$ program during the operational life of the repository to improve on the initial waste package design or to develop special packages (if needed) for the many different types of spent fuel from defense activities that might ultimately require direct disposal.

DOE-NE and the UFDC will consider the merits of deploying a similar R\&D type facility as progress towards the development of a national disposal facility is made. Such a facility could be used to evaluate the design concepts for packaging, handling, and emplacement of high level radioactive waste and spent nuclear fuel at design rates, and to establish operating capability without exposing workers to excessive radiation. Generically applicable tests regarding packaging, handling, and emplacement technology for high level radioactive waste forms and spent nuclear could be performed.

This facility could be coupled with other R\&D facilities that may be developed by DOE-NE for developing technologies for other aspects of advanced fuel cycles or could be coupled to an underground research laboratory (URL, discussed below).

\subsection{Knowledge Management}

The collection, categorization, and dissemination of information regarding disposal system performance is essential as the U.S. embarks on the investigation of a variety of potential geologic media and repository concepts for the disposal of SNF and HLW that could be generated under advanced fuel cycles. As pointed out by the Japan Atomic Energy Agency:

The exponential growth in the knowledge base (and associated documentation) for radioactive waste management is increasingly seen as a cause for concern in most national programmes.

This applies to the U.S. program in that not only a range of geologic environments but also a range of potential future nuclear fuel cycles and associated waste streams are being investigated. The development of a comprehensive and user-friendly knowledge management system is needed to organize the large quantities of data and information expected to result from these investigations..

The UFDC is developing a Disposal Systems Evaluation Framework (DSEF) that is intended to be a flexible systematic analysis and knowledge-management framework for evaluation of disposal system options for a wide range of potential future nuclear fuel cycles and used fuel disposition alternatives. This knowledge-management framework will also serve as a valuable communication tool for the community of producers and users of knowledge. 
The DSEF will (1) facilitate integration of UFDC process and system models and data, (2) enhance the UFDC to interface with other OFCT elements, and (3) provide rapid response capability to address information requests from DOE Management or other organizations.

The DSEF will encompass several decision-support analysis categories and tools:

- High-level simulator of waste-isolation performance of the disposal system. These are the GDSE models discussed above

- Sorter of disposal-system attributes (pros and cons). It is anticipated that the DSEF will be exercised for multiple disposal-system concepts for many of the combinations of waste forms (UNF and those being developed the Separations/Waste Form Campaign) and disposal-system environments listed above. Thus, a compilation of pros and cons for each situation will aid in grouping and contrasting various options.

- High-level estimator of disposal-system cost. This will use high-level estimating tools benchmarked to existing detailed cost estimates or actual costs.

- High-level thermal-analysis toolkit to assess geometric requirements (footprint, drift and wastepackage spacing) for the disposal system, based on specified thermal criteria (e.g., limits on peak temperatures of engineered components and the near-field). Once a geologic setting and waste form are selected for evaluation, thermal analysis is key to defining potential disposal-system layouts (single level, multi-level, in-drift, horizontal borehole, vertical borehole, deep borehole from the surface, etc.) and EBS concepts (capillary barrier, clay barrier, etc.).

- High-level assessment of overall system impacts of a disposal concept. The disposal system is one component of the overall fuel cycle. As such, it must interface with other components that may influence the disposal-system design requirements. Efforts will be made to integrate the DSEF with higher-level systems analysis tools being used and developed in the FC-R\&D arena (see below).

The DSEF will establish a UFDC knowledge management system to organize high-level information, data, and assumptions, thereby facilitating consistency in high-level system simulation and economic analyses.

International programs are developing knowledge management systems for their programs. Collaboration with these organizations will be sought. As an example, JAEA is performing non-site-specific R\&D activities that will ultimate support a site-specific safety/licensing case and is developing a knowledge management system. This is similar to the current situation in the U.S. and their experience in developing their knowledge management system could be beneficial in the development of the UFDC DSEF.

\section{$5.4 \quad$ Bibliography for Section 5}

H. Umeki, K. Hioki, H. Takase, I. McKinley, "Overview of the JAEA Knowledge Management System Supporting Implementation and Regulation of Geological Disposal in Japan,” Proceedings of the $12^{\text {th }}$ International Conference on Environmental Remediation and Radioactive Waste Management (ICEM'09), October 2009, ICEM2009-16354. 


\section{Site Selection and Characterization}

With the decision to no longer pursue the disposal of spent nuclear fuel and high level nuclear waste in a repository at Yucca Mountain, the U.S. will ultimately have to select and investigate other sites. The process for site selection and characterization is uncertain, however a wide range of geologic media are potentially suitable for the disposal of these materials. Site characterization historically has been a time consuming and expensive endeavor. Improved techniques and methods should be developed to support future site selection and site characterization efforts such that they can be done more quickly and at lower cost. Furthermore, risk-informed techniques and methods to identify the key data needs are needed to focus site selection and characterization programs to preclude unconstrained investigations. This would allow for the examination of multiple sites during a site selection process and more efficient characterization of any site chosen for continued study.

\subsection{Site Screening and Selection Tools}

The U.S. will consider several alternative rock types to host future geologic repositories. These rock types occur across large regions of the U.S.; however, viable geologic media considered for site selection could be limited depending on future criteria and guidelines adapted for site selection. International guidelines for siting a repository have been adapted by many countries over the years and include specification of a number of factors that could potentially adversely affect the safety of the repository and increase risk to humans and thereby reduce the number of viable locations. For example, international and U.S. siting guidelines have taken into consideration the presence of mineral resources, tectonic hazards, hydrologic features such as water bodies, recharge and discharge zones, and proximity to areas of high population density and transportation infrastructure as factors that influence site selection. It is not clear how the availability of particular host media would be impacted in the U.S. if different (and currently uncertain) site screening and selection criteria were applied in the future.

Siting of a geologic repository (or a centralized storage facility) ultimately involves a geospatial decision: where will the facility be located. Geospatial analysis tools at the regional and national scale would allow exploration of the implication of various siting guidelines to understand where potential host media are present, and how those locations would interact with future siting criteria or guidelines. Development of these tools should also provide a capability for initial and rapid site screening of any potential repository sites nominated by a future U.S. siting process, including possible volunteer sites.

\subsection{Experimental and Analytic Techniques for Site Characterization}

Experimental and analytic techniques pertaining to site characterization have evolved and improved both in the U.S. and other nations as geologic repository programs have matured. However, advances both in the disposal science and other geotechnical fields may lead to improved site characterization techniques that could be applied to future site characterization efforts. Further exploration, research, and development to identify potential experimental and analytic techniques that may prove useful.

The U.S. has extensive history in characterizing the WIPP and Yucca Mountain sites. The U.S. developed site characterization plans for other media during the early stages of the U.S. waste management. These, coupled with information from site selection and characterization efforts in other nations can provide insight into the type of information required and the techniques that could be applied. In addition, guidelines from the International Atomic Energy Agency may provide insight regarding techniques and criteria for consideration, especially given the uncertainty pertaining to U.S. guidelines. However, much of this information is dated, and more advanced techniques should be explored. 
Research and development in other areas may have developed experimental and analytic site characterization techniques that could be applicable to future geologic repository characterization efforts. These include the oil and gas industry, mineral mining, geothermal energy exploration, and geologic carbon dioxide sequestration. Advances in these areas should be investigated and the potential for collaborative research and development should be explored. Both non-invasive and invasive techniques, as well as applicability of specific techniques to specific media, should be explored.

International collaboration could also prove beneficial in developing advanced site characterization experimental and analytic techniques. Several international programs are underway or are planned, such as DECOVALEX and the FORGE project, where U.S. involvement may prove beneficial. Advanced experimental and analytic techniques could also be explored and tested in underground research laboratories (discussed in Section 6.3).

\subsection{Underground Research Laboratories}

Underground research laboratories (URLs) could be used to conduct experiments designed to address non-site-specific issues. While it can be difficult to translate information gained in URL studies to specific sites, there are aspects that would make such URL investigations more generally beneficial. A URL could be used to:

- supplement and focus a site characterization process;

- demonstrate a repository-like system;

- provide a means of identifying and resolving potential repository licensing issues;

- validate scientific models under actual conditions;

- provide analog information for specific sites having similar geology;

- refine design and engineering of repository components and systems;

- supplement siting data; and

- evaluate design concepts for waste packaging, handling, and emplacement.

In addition, if the U.S. foregoes repository siting for an extended period of time, studies in a domestic URL could help maintain repository development expertise. However, there may be a reasons (i.e., cost) not to develop URLs in the U.S. unless they are in geologic media where one does not currently exist elsewhere. Domestic fundamental R\&D needs could potentially be met by gaining access to URLs in other countries working in relevant geologic media through collaborative studies and experiments.

A number of other countries have developed, or are developing, underground research laboratories (URLs) as an important part of their repository development process (see Table 2 below). In some, but not all, cases the URLs are at sites that are not expected to develop into repositories. The Department of Energy cooperated in some of these activities before work on crystalline rock was terminated following the 1987 amendments to the Nuclear Waste Policy Act. These activities could be restarted.

Experimental activities conducted in URLs (and operations-related surface facilities) could potentially help improve public confidence through demonstrating fundamental understanding of disposal and operational concepts.

\subsection{Bibliography for Section 6}

International Atomic Energy Agency, Techniques for Site Investigations for Underground Disposal of Radioactive Wastes, Technical Report Series No. 256, IAEA, Vienna, 1985.

International Atomic Energy Agency, Site Investigations for Repositories for Solid Radioactive Wastes in Deep Continental Geological Formations, Technical Report Series No. 215, IAEA, Vienna , 1982. 
Nuclear Waste Technical Review Board, Survey of National Programs for Managing High-Level Radioactive Waste and Spent Nuclear Fuel, A Report to Congress and the Secretary of Energy, October 2009.

Table 2: Foreign Underground Research Laboratories

\begin{tabular}{|l|l|}
\hline Country & Underground Research Laboratory \\
\hline Belgium & Mol (clay) \\
\hline Canada & Pinawa (granite) \\
\hline Finland & ONKALO facility (granite) \\
\hline France & $\begin{array}{l}\text { Bure (argillite, a fine-grained sedimentary rock composed primarily of } \\
\text { indurated [hardened] clay particles ) }\end{array}$ \\
\hline Germany & Gorleben (salt) \\
\hline Japan & $\begin{array}{l}\text { Tono (granite) } \\
\text { Mizunami (granite) } \\
\text { Horonobe (sedimentary rock) }\end{array}$ \\
\hline Republic of Korea & Korea Underground Research Tunnel (granite, shallow depth) \\
\hline Sweden & $\begin{array}{l}\text { Äspö (granite) } \\
\text { Stripa (granite) }\end{array}$ \\
\hline Switzerland & $\begin{array}{l}\text { Mont Terri (clay) } \\
\text { Grimsel (granite) }\end{array}$ \\
\hline
\end{tabular}

Source: TRB 2009, Table 5. 